\title{
¿SON LAS FAMILIAS DE PALABRAS UN SUBPRODUCTO DE LA MORFOLOGÍA O ES LA MORFOLOGÍA UN SUBPRODUCTO DE LAS FAMILIAS DE PALABRAS?
}

\author{
Héctor Hernández Arocha \\ Universidad Europea de Canarias / Universität Erfurt
}

\section{RESUMEN}

El objetivo de este artículo es mostrar que los elementos semánticos tradicionalmente llamados «raíces» controlan decisivamente la estructura de las familias de palabras y, por lo tanto, representan algo más que un simple receptáculo de información idiosincrásica. Basado en un análisis semántico-categorial (Dowty / Wall / Peters 1981; Carpenter 1997; Steedman 2000, en preparación; Jacobson 2014; Lambek 2014; Baldridge / Frederick Hoyt 2015 y otros) de familias diatéticamente alternantes, trataremos de mostrar que (a) este y otros aspectos relacionados pueden reducirse al problema de definir el tipo lógico de raíces y (b) que este último regula la extensión de la familia y determina la semiproductividad atribuida tradicionalmente a la morfología.

Palabras Clave: raíces, semántica léxica, familias de palabras, restricciones morfológicas, gramática categorial.

\author{
ARE WORD FAMILIES A BY-PRODUCT OF MORPHOLOGY \\ OR IS MORPHOLOGY A BY-PRODUCT OF WORD FAMILIES?
}

Abstract

The aim of this article is to show that the semantic elements traditionally called «roots» decisively control the structure of word families and therefore represent more than a simple container of idiosyncratic information. Based on a semantic-categorical analysis (Dowty / Wall / Peters 1981; Carpenter 1997; Steedman 2000, in preparation; Jacobson 2014; Lambek 2014; Baldridge / Frederick Hoyt 2015 and others) of diathetically alternating families, we will try to show that (a) this and other related issues can be reduced to the problem of defining the logical type of roots and (b) that the latter regulates the family size and controls the semiproductivity traditionally attributed to morphology.

KEYwORDs: roots, lexical semantics, word families, morphological restrictions, categorial grammar. 


\section{INTRODUCCIÓN}

Recientemente, el concepto tradicional de «familia de palabras» se ha colocado en el punto de mira de la investigación lingüística por diversas causas (Cruse et al. 2002; Morera 2007; Gombocz 2013; Hernández Arocha 2014, 2016a, 2016b). Por un lado, la familia léxica representa una alternativa sugerente a modelos de organización mental del léxico ya establecidos, como el de los campos semánticos, el de los campos de acción (Handlungsfelder), el de los marcos semánticos (frames) o el de las redes asociativas ( $c f$. Augst 2000, 2009; García Padrón 2007; Morera 2007, Hernández Arocha / Batista Rodríguez / Hernández Socas 2011; Martín Padilla 2015); frente a estos últimos, el modelo familiar ofrece evidencia morfofonológica (lingüística) directa de la organización del léxico y esquiva así el escollo metodológico que suponen, con frecuencia, los tests indirectos de elicitación de datos que avalan la existencia cognitiva de relaciones semánticas (Rohlfing 2014: 11-29). Por otro lado, estas macroestructuras morfosemánticas comparten con los modelos citados la evidencia psicolingüística que se refleja en ámbitos tan dispares como el del reconocimiento de léxico, el family size effect (De Jong / Schreuder / Baayen 2000), el de la estructura de la memoria y el acceso léxico (Mulder / Dijkstra / Schreuder / Baayen 2014) o, incluso, el del cambio diacrónico y su correspondiente creación, concurrencia y pérdida léxicas (Splett 2009; Pena 2011; Hernández Arocha 2014).

Todos estos datos apuntan a un problema central: ¿cuál es el estatus exacto de estas estructuras? ¿Representan el simple residuo histórico de mecanismos morfológicos (semi)productivos en diversas épocas o son, más bien, el germen que explica la productividad o -tomando otra metáfora- el código genético de acuerdo al cual se realiza la variedad morfológica?

En este estudio defendemos la hipótesis de que la respuesta a estas preguntas depende crucialmente del estatus que le asignemos a la raíz léxica (Hernández Arocha $2016 b$ y en preparación). De hecho, existe un amplio consenso en la Wortfamilienforschung alemana, así como en los desarrollos más recientes de los estudios sobre familias en el mundo románico, en que la diferencia esencial entre un campo semántico y una familia léxica radica en sustituir el concepto de archisemema por el de raíz.

Por todo ello, si adoptamos una perspectiva (neo)construccionista, en la que las raíces, en el mejor de los casos, se reducen a un mero receptáculo de información enciclopédica, sin capacidad productiva (Hale / Keyser 2002: 254; Acedo-Matellán / Mateu 2014: 17; Mateu 2014: 29) y, en el peor, están desprovistas de contenido semántico y determinadas únicamente por contenido fonológico (Borer 2014a: 356, 2014b: 115), entonces, la importancia del concepto de familia léxica se desvanece y las causas por las que estos "constructos residuales» desempeñan un papel tan importante en el procesamiento mental del lenguaje parecen cada vez más indescifrables. Si, por el contrario, asumimos una postura (radicalmente) lexicalista, en la que se enfatice la naturaleza (también) algebraica de estructuras léxico-semánticas controladas por la raíz e independientes de la sintaxis explícita, la importancia de las familias de palabras se realza, especialmente en lo que respecta al procesamiento 
del lenguaje, de modo que nuestra impresión abandona el dominio metafórico de los "fósiles», abrazando, entonces, el de los «organismos vivos».

Basándonos en un análisis semántico-categorial (Dowty / Wall / Peters 1981; Carpenter 1997; Steedman 2000, en preparación; Jacobson 2014; Baldridge / Frederick Hoyt 2015) de familias diatéticamente alternantes, intentaremos mostrar que (a) esta y otras cuestiones relacionadas se reducen al problema de considerar el tipo lógico de las raíces y (b) que este último regula la extensión de la familia (family size) y controla, de un modo decisivo, la semiproductividad tradicionalmente atribuida a la morfología.

Para apuntalar estas dos hipótesis expondremos, primero, algunos argumentos a favor y en contra de ambas aproximaciones para pasar, luego, a presentar un análisis concreto de dos de las raíces estadísticamente más prominentes del español en el dominio semántico de la locución. Finalmente, expondremos algunas conclusiones extraídas de los datos.

\section{EL CONCEPTO DE RAÍZ ENTRE EL LEXICALISMO Y EL CONSTRUCTIVISMO}

Como pone de manifiesto Gallego (2014: 192), desde el origen del lexicalismo (Chomsky 1972 [1970]) hasta las más recientes propuestas (neo)construccionistas (Hale / Keyser 2002; Ramchand 2008; Borer 2013, entre otros), no ha cesado la discusión en torno a la naturaleza y tipología de las raíces léxicas. Desde la discusión sobre si estas unidades están almacenadas en la memoria ya categorizadas o, por el contrario, desprovistas de rasgos categoriales, pasando por el tipo de formato que se impone al contenido léxico o por la problemática en torno a si presentan o no matriz fonológica, hasta llegar al problema de si tales primitivos léxico-semánticos proyectan estructura argumental, difícilmente se ha llegado a un consenso sobre la naturaleza, formato y propiedades de tales unidades (para un sucinto panorama ilustrativo de modelos y aproximaciones, véase Alexiadou / Borer / Schäfer 2014). Sin embargo, frente a esta diversidad de opiniones y haciendo abstracción de discrepancias conceptuales menores, parece existir un amplio consenso en cuanto a dos aspectos (Gallego 2014: 192):

a) Las raíces están desprovistas de categoría gramatical.

b) Las raíces almacenan contenido léxico-enciclopédico, no algebraico.

Mientras que la hipótesis que encarna (a) no parece haberse ramificado conceptualmente ${ }^{1}$, al considerarse que es el «entorno sintáctico» (el categorial com-

${ }^{1}$ Con todo, en Hernández Arocha (2016b) se intenta evaluar, desarrollando algunas ideas de Batista (comunicación personal), hasta qué punto las raíces están totalmente exentas de categoría o si, por el contrario, contienen algún tipo de información en potencia que oriente su manifestación 
plement space, en el sentido de Borer 2013: 313) el encargado de especificar la categoría de la raíz, la segunda suposición (b) ha sido objeto de un debate considerablemente más intenso. De hecho, y que tengamos constancia, poco se ha dicho sobre el formato en el que se encuentra organizado tal contenido enciclopédico. En este sentido, Dowty (1979) propuso, basándose en Montague (1970), que toda raíz (contenido léxico idiosincrásico o "constante no lógica», en su terminología) representaba una instanciación de un «estado» abstracto, esto es, podía reducirse a un átomo predicativo monomembre de carácter estativo, como instanciación particular de la función ${ }^{2}\left(\{0,1\}^{\mathrm{De}}\right)^{\mathrm{I} \times \mathrm{J}}$. Siendo así las cosas, los estados representarían residuos informativos sin (sub)estructura lógica que sirven de «ladrillos» para conformar eventos lógicamente complejos, de modo tal que, por sí solos, caerían fuera del alcance del análisis aspectual. En palabras del propio Dowty:

The intuition behind the aspect calculus is of course that stative predicates are somehow simpler or more limited in their interpretation than other kinds of verbs, hence it is an interesting enterprise to try to figure out how non-statives can be constructed out of statives in a tightly-constrained way (Dowty 1979: 126).

Quizá sea interesante mencionar que esta idea, si bien no ha gozado de consenso en la lingüística general posterior, ha sido mantenida fehacientemente por la lingüística histórica y, en particular, por la lingüística indoeuropea. Así, a diferencia de la tendencia latino-romance, el tema de presente en indoeuropeo es morfológicamente derivado, mientras que el tema de aoristo es morfológicamente simple, como se aprecia con claridad en griego clásico: considérese que $\lambda \alpha(\mu) \beta(\alpha \dot{\alpha} v) \omega$ ('coger' en presente, semánticamente un accomplishment) presenta un aoristo (है) $\lambda \alpha \beta(\mathrm{ov})$, procedente de la raíz $\lambda \alpha \beta$ - ('estar sujeto'); y, como este, constituyen también una prueba sólida todos aquellos verbos con infijo en el tema de presente, reducibles a un estado a nivel de la raíz. Esto ha llevado a autores como Batista/Tabares (2011) a afirmar que, en griego clásico, el tiempo es un modificador del aspecto, siendo el aspecto la categoría base, mientras que, en las lenguas romances, el aspecto es un modificador del tiempo, constituyendo esta última la categoría elemental. Ahora bien, más allá de la evidencia formal e histórica que parece apuntalar la suposición de Montague/ Dowty, no existen propuestas que esclarezcan con mayor profundidad el formato (si es posible, universal) en el que se encuentra codificado este contenido idiomático.

categorial en algún sentido y que explique la razón de ser de la desproporción que existe entre unas manifestaciones categoriales y otras, más allá de la mera alusión a la «norma».

${ }^{2}$ De acuerdo con Montague (1974 [1970]: 228, 258), esta función asigna índices o intensiones representadas como pares ordenados de mundos posibles (I) y contextos de uso o instantes (J) al conjunto de denotaciones (D) verificables para un individuo o entidad (e). En otras palabras, esta función especifica el conjunto de mundos/instantes posibles en los que la denotación de cada individuo se verifica. 


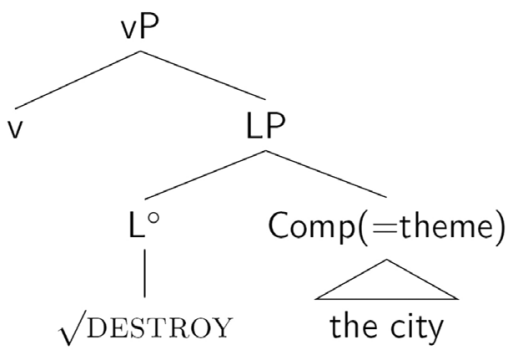

Fig. 1. Nominalización del $\sqrt{ } \mathrm{P}$ construct the house según Harley (2009: 329-332).
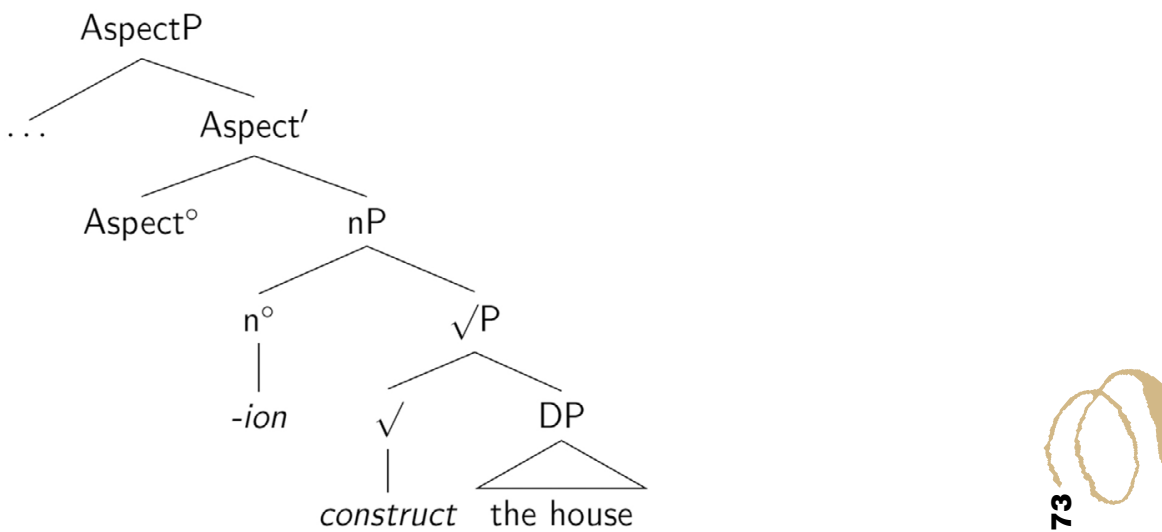

Fig. 2. Estructura sintáctica subyacente de destroy the city según Alexiadou (2001: 17), análoga a la propuesta en Marantz (1997: 217).

Por otra parte, en lo que concierne a su proyección sintáctica, no está claro en la discusión actual si las raíces proyectan estructura argumental (valencia) o si están desprovistas de ella. Excluyendo el caso de los agentes o argumentos externos, cuya denominación radica, de hecho, en la hipótesis de que estos se generan externamente a la proyección verbal que alberga el contenido léxico de la raíz, existen autores como Marantz (1997: 2017), por ejemplo, para quienes las raíces pueden asumir un argumento interno (el objeto de la acción) antes de ser verbalizadas e, incluso, proyectarse como sintagmas (léxicos: $\sqrt{ } \mathrm{P}$ o L (ex)P). Esta postura la comparten autores como Alexiadou (2001: 17-20) o Harley (2009: 329-332), como se aprecia en las figuras 1 y 2.

Más recientemente, en el interesante debate que recogen Alexiadou / Borer / Schäfer (2014), esta hipótesis la defienden también Levinson (2014: 224), Lowenstamm (2014: 245) y Roßdeutscher (2014: 290), por solo citar algunos ejemplos. Sin embargo, esta aproximación dista mucho de ser unánime. Más tarde, el pro- 


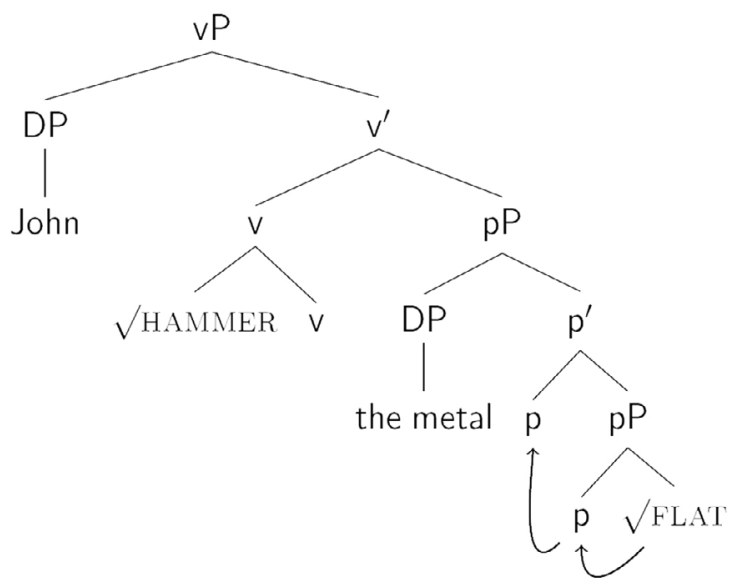

Fig. 3. Estructura sintáctica subyacente de la oración John hammered the metal flat según Acedo / Mateu (2014: 31).

pio Marantz (2001), también en colaboración con Embick en 2008, renuncia a esta hipótesis en favor de la idea de que las raíces se categorizan antes de la introducción de los argumentos, que se insertan en las posiciones hábiles en la estructura sintáctica en la que la raíz se encuentra incardinada. Como consecuencia, las raíces no son capaces de proyectarse como sintagmas, como veíamos anteriormente. Entre los defensores de esta segunda hipótesis se encuentran Acedo-Matellán / Mateu (2014: 115ss.), Borer (2014a: 115ss.), Gallego (2014: 197ss.) y muchos otros. Así, en la fig. 3, tanto la raíz que determina la manera (hammer) del evento verbal principal como la raíz que evoca el estado resultante ( flat) funcionan como modificadores de proyecciones sintácticas que habilitan posiciones argumentales que, una vez saturadas con la semántica de sus argumentos, hacen de las raíces eventos dinámicos y resultativos, respectivamente. Dicho de otra manera, las raíces no son dinámicas o estativas por sí mismas, sino por la estructura que las acoge, que, junto a una interpretación, les confiere también una categoría.

Llegados a este punto, parece bastante convincente la argumentación en favor de la interpretación "estructural» que ofrece la sintaxis y cómo el entorno sintáctico asigna una categoría a su «espacio complementario», esto es, al dominio de la función que define la proyección sintáctica. No obstante, creemos que es lícito hacerse una pregunta más básica -o, si se quiere, elemental- a propósito de estas aproximaciones: ¿qué es $\sqrt{ }$ ?

Si $\sqrt{ }$ (una raíz) es la abstracción conceptual de una palabra o signo (léxico, semiléxico o gramatical) simple, con la única diferencia de que se le despoja de categoría, entonces, ¿qué tipo de signo lingüístico es $\sqrt{ }$ ?

Creemos que una cosa debe estar clara: si, de acuerdo con los modelos expuestos, un signo es lo que manipula o computa la sintaxis y la sintaxis manipula 
raíces, entonces se sigue que las raíces deben ser, necesariamente, signos. De este modo, sin entrar a debatir las propuestas de morfología distribuida que no le reconocen fonología a las raíces, podemos estar seguros de que, definidas como pares de sonido/significado computables por la sintaxis, las raíces presentan una indudable naturaleza sígnica. Dedicaremos el siguiente apartado precisamente a intentar clarificar a qué clase(s) pertenecen las raíces.

\section{LA CATEGORÍA DE LAS RAÍCES}

\subsection{LaS Raíces y la PaRAdoja DE RuSSELl}

En una gramática categorial, que, como instanciación particular del dominio matemático de la Teoría de Categorías, opera necesariamente con funciones, nada puede ser sometido a procesamiento sintáctico si no está sujeto a una determinada categoría o, dicho de otro modo, si no es susceptible de definirse algebraicamente. Siendo así las cosas, ¿cuál es la categoría de $\sqrt{ }$ ? Piénsese que, como ha puesto de relieve Steedman (2000), la gramática combinatorio-categorial genera débilmente el mismo lenguaje que el modelo de gramática expuesto en el programa minimalista (Chomsky 1995), de modo que no solo es equivalente, sino que, además, comparte con él también su filosofía: reducir a un mínimo indispensable los mecanismos universales de producción de oraciones, demostrar que tales principios responden a un diseño óptimo caracterizador del lenguaje humano y, no por último, asignar todo aspecto paramétrico, idiosincrásico o irregular del lenguaje al léxico, de modo tal que este represente el repositorio de todo lo que el niño tuvo que haber almacenado en su memoria para restringir su capacidad de aprender cualquier lengua a la competencia actual de la lengua que aprendió.

Precisamente, si se pretende mantener esta filosofía minimalista, creemos que la sintaxis no debería ser ciega ni a la fonología ni a la categoría/tipo del objeto que manipula. De hecho, si se permitiera esta primera propiedad, i. $e$., la de que las raíces carezcan de fonología, obtendríamos consecuencias catastróficas para modelos distribuidos, en los que las raíces tienen que esperar a que actúe la sintaxis para recibir la interpretación fonológica del contenido computado (al alcanzar la lista 2; cf. Marantz 1997: 204). Así, la mente podría computar sintácticamente cualquier contenido de consciencia sin percatarse de que no es expresable lingüísticamente hasta que, en el momento de la exteriorización (spell-out), no encuentre manifestación fonológica de aquello que ha procesado. De hecho, si el lenguaje se fundamenta en el procesamiento de objetos no definidos fonológicamente, el tiempo de computación aumentaría sobremanera, dado que se incrementaría al procesar $k^{\infty}$ (para $k=|\mathrm{V}(\mathrm{S})|$ ), es decir, la cardinalidad del vocabulario contenido en una oración elevada al conjunto infinito de contenidos de consciencia que podrían expresarse, pero que no lo hacen en la lengua dada para tal oración. O, expresado de otro modo, la complejidad del procesamiento lingüístico supondría el número de nodos sintácticos terminales elevado al conjunto infinito de contenidos de consciencia posibles por cada nodo. Este hecho me parece aun peor que el de sobregenerar, dado que se 
pasaría del problema de haber definido un conjunto finito, pero que es mayor o parcialmente distinto del que se pretende definir, a postular un conjunto infinito que tiene que ser comprobado y escindido entre lo expresable e inexpresable lingüísticamente antes de empezar a hablar (esto es, a "pronunciar»).

Este problema se reduciría si permitiéramos que las raíces comiencen la derivación sintáctica con fonología, es decir, con significante, formando así signos, de modo que, sabiendo ya cuáles son los ítems léxicos exactos que estamos computando, reduzcamos su complejidad de $k^{\infty}$ a $k^{n}$ (para $k=|\mathrm{V}(\mathrm{S})|$ ), o el número de raíces léxicas determinadas ocupando nodos sintácticos terminales y $n=$ el número de categorías gramaticales permitidas en el lenguaje ${ }^{3}$.

Por otro lado, estando las raíces privadas de categoría, se llegaría a la situación paradójica de que, en el conjunto total de categorías computables por la sintaxis, tendríamos un subcojunto propio de elementos con categoría, i.e., las categorías gramaticales, y un subconjunto complementario de categorías, i.e., las raíces, que satisfacen la propiedad de no ser categorías. Visto el problema desde esta óptica, la argumentación «desfonologizadora y descategorizadora» de las raíces -aparentemente trivial e indemne- parece introducir en una sintaxis bien definida el mismo tipo de problema que supuso la introducción de la paradoja de Russell en la teoría de conjuntos: parece evidente que, así como la introducción en teoría de conjuntos de la clase de conjuntos que no son conjuntos de sí mismos presenta, a pesar de su apariencia inocua, consecuencias nefastas, estas mismas consecuencias se desencadenarían al introducir en el sistema algebraico de generación de oraciones una clase de categorías sintácticas que no son, propiamente, categorías sintácticas.

\subsection{LAS RAÍ́CES Y SU CATEGORÍA SEMÁNTICA}

Existen modelos que, sin embargo, toman una decisión menos drástica a la hora de definir el formato lingüístico de una raíz. Como hemos visto, la solución de privar signos de categoría gramatical y representación fonológica no parece facilitar al hablante la tarea de producir y comprender el lenguaje. Bien al contrario: sería oportuno inducir categorías o tipos en las raíces para aligerar su procesamiento. La idea más simple es la propuesta por Montague/Dowty y expuesta sucintamente supra: tratar raíces como funciones de tipo (1), es decir, como funciones que proyectan índices ( $i=I \times J$, en concreto, pares ordenados de intervalos y mundos posibles) a la función de un individuo (e). En una lógica extensional, bastaría con eliminar el índice a la función del individuo para seguir operando con esta categoríal tipo semántico de forma esperable.

$$
\sqrt[V]{ }:=\langle i,\langle e, t\rangle\rangle
$$

\footnotetext{
${ }^{3}$ Agradezco a Guillermo Zecua sus interesantes apreciaciones a este problema.
} 
Esta decisión difiere sustancialmente de las expuestas hasta ahora. Por un lado, las raíces, si bien pueden estar desprovistas de categoría gramatical (sustantivo, verbo, etc.), no están desprovistas de categoría semántica. De hecho, la categoría de una raíz estativa como (1) sería aquella que comprueba todos los mundos posibles para los que se da el caso de que un individuo satisface una propiedad, determinando así, por tanto, la «intensión» de la clase a la que pertenece tal individuo. En concreto, (1) especifica una "propiedad» predicativa. Como es sabido, son los sustantivos comunes, los verbos intransitivos y los adjetivos los que expresan semánticamente una "propiedad", de modo tal que la semántica orienta las posibilidades categoriales de la gramática.

Propuestas como las de Levinson (2014) o Roßdeutscher (2014) representan desarrollos de esta perspectiva, si bien no consideran que toda raíz deba constituir necesariamente un estado, como veremos a continuación. Por ejemplificar este tipo de modelos con un ejemplo, tomemos la propuesta de Levinson. Para esta autora, existen al menos tres tipos (extensionales) de raíces dependiendo de cómo estas se comportan en construcciones pseudorresultativas, ditransitivas y de objeto facultativo, respectivamente (tabla 1). En el primer caso, la raíz representa un tipo semántico $\langle e, t\rangle$, una propiedad de un individuo; en el segundo caso, tenemos un tipo $\left\langle s_{e}, t\right\rangle$, a saber, una propiedad de un evento; el tercero codifica la función de un individuo para la propiedad de un evento, esto es, $\left\langle e,\left\langle s_{e}, t\right\rangle\right\rangle$.

\begin{tabular}{lcccc}
\hline \multicolumn{5}{c}{ TABLA 1. TIPOS DE RAÍCES SEGÚN LEVINSON (2014: 229) } \\
\hline \multicolumn{5}{c}{ SUmmary OF Root Types ANd Verb Behavior } \\
\hline \multicolumn{1}{c}{ Verb Type } & Pseudo-resultatives & Double Objects & Obligatory Theme & Root Tyope \\
\hline Root Creation & $\checkmark$ & $*$ & Yes & $\langle e, t\rangle$ \\
\hline Explicit Creation & $*$ & $\checkmark$ & No & $\left\langle s_{e}, t\right\rangle$ \\
\hline Change of State & $*$ & $\checkmark$ & Yes & $\left\langle e,\left\langle s_{e}, t\right\rangle\right\rangle$ \\
\hline
\end{tabular}

El primer tipo codifica raíces que denotan la semántica de un objeto que se crea mediante la realización de la actividad que designa el verbo que las acoge. Representan, resumiendo, la raíz de verbos tradicionalmente considerados denominales, en los que el objeto que se crea es el denotado por la raíz verbal. Es el caso de oraciones como ( $2 \mathrm{a})$, en las que la entidad que se crea no es el objeto directo, sino la denotada por la raíz verbal. De este modo, (2a) no denota 'el estilista le hizo el pelo con una trenza', sino 'el estilista le hizo una trenza con el pelo'.
a. The stylist braided her hair.
b. The stylist braided her hair tight.
c. ${ }^{*}$ The stylist braided her her hair.
d. *The stylist braided $\varnothing$ for hours.

En estos casos, la raíz representa la propiedad que asume el objeto mediante la acción abstracta que lleva a cabo el agente, es decir, algo como 'el estilista hace que 
su pelo se convierta en una trenza'. Al ser la misma raíz una propiedad, se interpreta que es tal propiedad la que asume el objeto mediante la acción del sujeto; pero además, siendo una propiedad, puede experimentar una modificación intersectiva si se le adjunta otra propiedad con la misma categoría semántica (aunque difiera en su categoría gramatical). De este modo, si se le añade un predicativo, por ejemplo, un adjetivo como tight, la construcción no significará que 'el estilista hace que su pelo esté tenso haciéndole una trenza', sino, por el contrario, 'hacer que el pelo se convierta en una trenza tensa'. En otras palabras, el adjetivo se predica de la raíz verbal y no del objeto, como sí ocurre en construcciones como las que observábamos en la fig. 3 o en $(3 \mathrm{~b})$, que denota la relación inversa ( $c f$. 'hacer que el metal esté plano, martilleándolo / * 'hacer que el metal se convierta en un martillo plano') y en las que, por el contrario, puede introducirse un beneficiario (2c) o eliminarse el predicativo $(2 \mathrm{~d})$.
a. The smith hammered the metal (in five minutes).
b. The smith hammered the metal flat.
c. The smith hammered him the metal.
d. The smith hammered the metal for hours.

Esto ocurre porque, en los casos citados, la raíz denota una categoría de tipo $\left\langle s_{e}, t\right\rangle$, es decir, denota la propiedad de una situación eventiva o actividad ejecutada por el sujeto. La raíz matiza el tipo de actividad llevada a cabo por el agente (cf. fig. 4). Por lo tanto, dotada de esta categoría, la raíz no podrá sufrir una modificación intersectiva con un predicativo, para dar lugar a una lectura pseudorresultativa como (2b). Sin embargo, ¿qué ocurre con las raíces estativas como $V_{\text {open, que, }}$ insertas en un dominio verbal incoativo, denoten un cambio de estado? Este tipo de raíces se parece a las de creación en tanto que predican información de un argumento, pero difieren de ellas en que, una vez insertado, verifican un evento y no una propiedad. Así, pueden ser insertadas en el complemento de un verbo (ligero) incoativo, dado que el operador de cambio de estado requiere, precisamente, que aquello que experimente el cambio sea un estado, ya verificado, y no una propiedad (cf. fig. $\left.5^{4}\right)$.

La aproximación de Levinson es interesante no solo porque dé cuenta de tres tipos de construcciones lingüísticas de considerable complejidad, sino porque, además, pone de manifiesto un hecho que parece falsear la hipótesis (b) de la que habíamos partido: vemos ahora que las raíces no solo introducen en la sintaxis contenido enciclopédico, sino que también inducen subestructura algebraica al asumir argumentos y al modificar eventos. De hecho, nótese que la apariencia «no composicional» de las raíces en la figura 3 es un espejismo notacional que desaparece en cuanto sometamos la estructura al cálculo lambda y descubramos que $\sqrt{\text { flat }}$ es un

${ }^{4}$ La figura original 5 presenta una errata al componer el complemento. La derivación comienza con «a beer» y, una vez aplicado el objeto, se integra como «the door». Léase, pues, «a beer» en su lugar. 


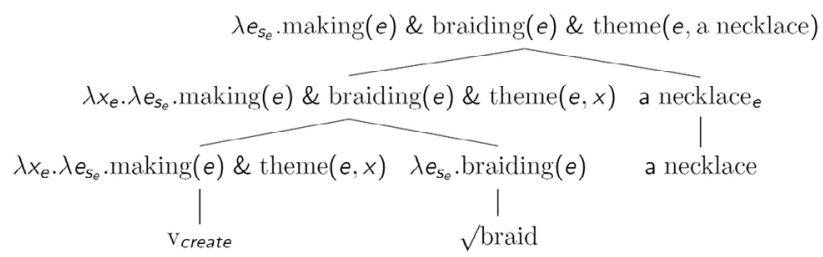

Fig. 4. Derivación semántica de to braid a necklace según Levinson (2014: 229).

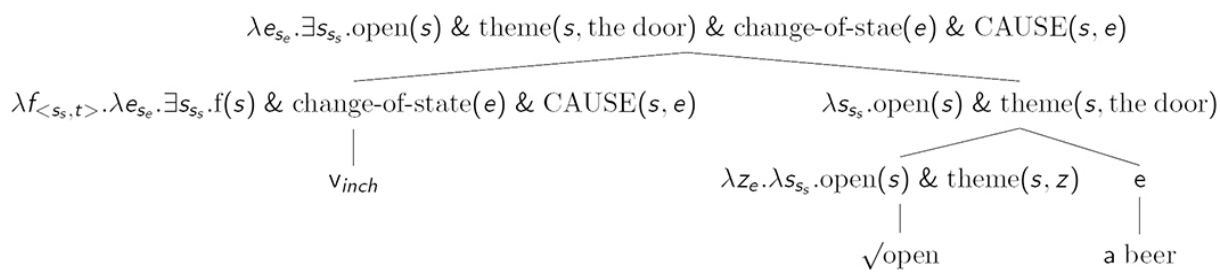

Fig. 5. Derivación semántica de to open a beer según Levinson (2014: 225).

predicado de primer orden, que no solo debe ascender a $p$ para comprobar sus rasgos, sino que asciende también porque, en tanto que predicado, debe transferir sus rasgos semánticos a su argumento, generado en la posición de especificador, esto es, el sintagma the metal. De no ser así, la estructura semántica se colapsaría al continuar la derivación sintáctica y no encontrar argumento que verifique la función de $p$. Por otro lado, siguiendo este razonamiento, vemos, entonces, que $\sqrt{h a m m e r}$, en tanto que modificador, es una función de segundo orden definida para el operador de actividad denotado por el verbo ligero al que se adjunta (e incorpora mediante conflation), de modo que denota así manera.

En resumen, el hecho de que la notación arbórea nos evite tener que especificar el álgebra que define una raíz no nos exime de definir la función que esta desempeña en la estructura sintáctica, la cual se vuelve evidente una vez que intentamos someterla al cálculo lambda. Además, siendo esto así, la complejidad de procesamiento se reduce, dado que el hablante ya no tiene que comprobar todas y cada una de las categorías que le ofrece el lenguaje y que podría asumir la raíz para su espacio complementario, sino que se restringe al número de categorías que, de acuerdo al espacio complementario, son hábiles para su función semántica. Definida técnicamente, una raíz no representaría una metavariable definida para abstraer cualquier función, esto es, una metavariable que abstrae (ranges over) el cálculo lambda, de complejidad discretamente infinita, sino que especificaría el conjunto mínimo de categorías aptas para su espacio complementario. Ahora bien, si, al reaceptar la fonología para las raíces (al menos léxicas) y al asignarles tipos semánticos, le devolvemos a la semántica léxica su estatus algebraico o composicional, ¿estamos volviendo con esta propuesta al lexicalismo? Esta cuestión la responderemos al final 
del trabajo, cuando ya hayamos sometido a análisis todos los datos que nos proponemos estudiar.

Queda, sin embargo, un aspecto que debemos mencionar antes de avanzar, a saber, la razón por la que, como apuntan Acedo-Matellán / Mateu (2014), la raíz $\checkmark$ hammer puede insertarse como complemento de $p$, dando lugar a una lectura télica.

En modelos eminentemente semánticos como los expuestos en este apartado, las raíces reciben una única categoría, un único tipo semántico definible en una expresión lambda. El problema de esta aproximación radica en que, si una raíz llegara a aparecer en varias construcciones, como vemos en (3), cada tipo de construcción precisaría un tipo semántico diferente, de modo tal que la raíz que codifica la lectura télica listada en (3a) presentaría un tipo lógico diferente de la que verbaliza la lectura atélica de (3d). La consecuencia de esta alternancia en el tipo semántico (con correspondencia en su tipo gramatical, que determina la incidencia en la estructura sintáctica) sería la de tener dos signos homónimos, a pesar de compartir un mismo significante fonológico. Este no es, por supuesto, un efecto deseable, dado que amplía el léxico e implementa la memoria en la adquisición, pero es el precio que tenemos que pagar por ir más allá en la comprensión de la subestructura que subyace a $\sqrt{ } \mathrm{y}$, en definitiva, por defender la hipótesis de que tal subestructura existe.

Sin embargo, estamos convencidos de que la teoría semántica no debe detenerse en este punto y que debería avanzar hacia un modelo de raíz que evite la multiplicación de homónimos, de modo tal que en ningún caso se produzca un incremento de la memoria durante la adquisición. Y si, además, pudiéramos defender la hipótesis de que, en esencia, toda raíz puede ser reducida a un único tipo (o formato) semántico, a ser posible universal, que varíe dependiendo del contexto, pero que ello no nos obligue a escindir unidades en el léxico, habremos llegado a una solución satisfactoria, pensamos, para cualquier modelo. Este será nuestro objetivo para el siguiente apartado.

\section{HACIA UN FORMATO UNIVERSAL DE RAÍZ}

En diversos trabajos anteriores (Hernández Arocha 2014, 2016a, 2016b), he propuesto la idea de que, en esencia, cualquier raíz puede reducirse a un y solo un tipo lógico, que desencadena múltiples efectos cuando interactúa con los dominios de la cognición y la sintaxis. El formato de toda raíz -in abstracto-sería la siguiente función intensional de segundo orden:

$$
\left(\{0,1\}^{\mathrm{s}^{\mathrm{D}}}\right)^{\left(\{0,1\}^{\mathrm{D}_{e}}\right)^{\mathrm{IxJ}}}
$$

Lo que representamos en (4) es, como decimos, el formato universal de toda raíz, concebida técnicamente como la intensión de la función de verificación de una entidad proyectada a la función de verificación de tal entidad. En palabras más simples, una raíz determina cuál es la intensión de un predicado para después modificarlo e imponerle restricciones. Su tarea es, por tanto, dar instrucciones sobre cómo tiene que interpretarse el evento o la situación en el que ella misma incide. De 
este modo, una raíz es a un evento lo que un adverbio es a una oración, esto es, un modificador o restrictor de la denotación expresada. En consecuencia, (4) define la clase a la que pertenece toda raíz o, si se quiere, su tipo lógico. Ahora bien, tal y como está expresado, es importante destacar que (4) no define ninguna raíz en concreto de un lenguaje natural, sino -como esqueleto lógico básico- la complejidad o el coste computacional que le supone a un hablante operar con ella. Para que (4) represente una raíz concreta de una lengua particular, es necesario imponerle restricciones, pasar del plano universal al plano histórico o idiosincrásico del lenguaje, usando los términos de Coseriu (2007 [1981]). De nuevo, no creemos que sea necesario un conjunto infinito de rasgos, una clase abierta, para acotar formalmente la idiosincrasia de una raíz. Estamos convencidos -y postulamos aquí como hipótesis, como también hemos hecho en otros lugares, $c f$. Hernández Arocha (2016a, b)de que los mecanismos que permiten pasar del formato universal al particular son mínimos y pueden clasificarse en los siguientes:

\section{(A) Rasgos estructurales}

Este tipo de rasgos se refiere a lo que Wunderlich (2012), basado en diversas propuestas de Kiparsky, ha definido como el grado de incrustación de un argumento en una estructura argumental. Para su análisis, este autor se vale de la alternancia $[ \pm h, \pm 1]$. El rasgo $[ \pm$ h(igher argument)] da cuenta de la existencia $(+)$ o inexistencia (-) de un argumento que ocupe una posición jerárquicamente más prominente en la estructura lógica/sintáctica que el argumento marcado con ese rasgo. Su relación inversa la representa el rasgo [ \pm 1 (ower argument)], que denota, consecuentemente, el hecho de que exista un argumento más incrustado o jerárquicamente menos prominente en la estructura lógica/sintáctica. Así, si un argumento dado está marcado con los rasgos [+h, -1], entonces este ocupará la posición argumental más baja en la estructura, dado que existirán otros argumentos generados en posiciones más prominentes, pero no habrá ningún otro generado por debajo de él. Por el contrario, los rasgos $[-h,+1]$ denotan que el argumento marcado de esta forma es el más prominente y que, por tanto, no está subordinado a ningún otro argumento, pero existen, con todo, argumentos por debajo de él. Los rasgos $[+\mathrm{h},+1]$ denotan que tal argumento ocupa una posición intermedia, existiendo al menos uno más prominente y otro subordinado. Los rasgos [-h, -1] son triviales, dado que nos advierten que solo existe un único argumento. Teniendo en cuenta que todo sistema de marcación busca definir la función característica requerida haciendo uso del menor número posible de medios, podemos concluir que, si lo que nos interesa de este sistema es su capacidad de definir la prominencia máxima o mínima, nos bastará marcar los argumentos estructurales o bien con $[-\mathrm{h}]$ o bien con [-1]. 
El rasgo atencional o focalizador $(\bullet)$ tiene la función de poner de relieve alguno de los argumentos de la estructura argumental y, al resaltarlo, define el segmento eventivo que se realiza en la sintaxis explícita. En este sentido, este rasgo es el que determina el HEAD eventivo, en el sentido de Pustejovsky (1995). Al mismo tiempo, tiene la función de definir lo que la lingüística cognitiva denomina "patrón de lexicalización", esto es, proyecta o lexicaliza segmentos del marco semántico que selecciona y hace desvanecerse en un segundo plano aquellos argumentos que no son objeto de focalización. Así, el rasgo $(\bullet)$ tiene la propiedad colateral de funcionar como un operador de ligamento, vinculando con el operador lambda $(\lambda)$ la variable marcada, propulsándola así hacia la sintaxis explícita, y cuantificando existencialmente $(\exists)$ el resto de argumentos no marcados. El rasgo atencional está sujeto, con todo, a dos restricciones principales: (1) no es iterable (solo es aplicable una vez), dado que, de otro modo, no podría crear el efecto de figura-fondo y (2) solo es aplicable a los contornos externos del evento y su adyacencia estricta. Es decir: si tenemos un evento con una estructura argumental de cinco variables $\left(x_{1}, \ldots, x_{i}, \ldots, x_{5}\right)$, entonces, $\bullet$ es aplicable a $x_{1}, x_{5}$ y cualquier $x_{i}$ a excepción de $x_{3}$. Si es de seis variables, a todas a excepción de $x_{3}$ y $x_{4}$, etc.

\section{(C) RAsgo Cognitivo-enCiCLopédico}

Este rasgo selecciona el conjunto de escenas cognitivas para las que hay una determinada expresión léxica en la lengua histórica que se define. Se corresponde con el rasgo de campo o archisemema en la semántica estructural. En toda lengua hay, por tanto, un conjunto finito $\mathrm{P}_{1}, \ldots, \mathrm{P}_{k}$ de predicados cognitivos como DESPLAZAMIENTO, ESTADO, PERCEPCión, LOCUCión, etc., a los que las raíces se refieren. Una raíz seleccionará, entonces, uno cualquiera de estos predicados $\left(\mathrm{P}_{i}\right)$ e impondrá restricciones sobre sus argumentos conforme a lo dicho en $(\mathrm{A})$ y verbalizará un segmento de tal marco semántico con ayuda de (B).

Definidas de este modo, las raíces representan, por un lado, la interfaz entre la cognición general y la semántica de la lengua particular y, por otro, el mecanismo que pone en un formato legible para la sintaxis la información que proviene de nuestras representaciones mentales, de modo tal que funcione también como interfaz semántica/sintaxis. A modo de resumen, una raíz de una lengua histórica presentará el siguiente formato (5), es decir, escogerá la intensión de un predicado cognitivo dado de los expresables en la lengua que se trate e impondrá sobre alguno de sus argumentos la propiedad de estar focalizado y, por ello, de proyectarse necesariamente hacia la sintaxis explícita.

$$
V:=\left\langle\left\langle i,\left\langle e_{[ \pm \mathrm{h}, \pm 1]},\left\langle s, \mathrm{t}_{\left[+\mathrm{P}_{i}\right]}\right\rangle\right\rangle\right\rangle,\left\langle\bullet e_{[ \pm \mathrm{h}, \pm 1]},\left\langle s, t_{\left[+\mathrm{P}_{i]}\right.}\right\rangle\right\rangle\right\rangle
$$

Si estamos en lo cierto, (4) representa la complejidad computacional de cualquier raíz, independientemente de la lengua particular, mientras que (5) pone 
de manifiesto cuál es el formato de cualquier raíz en una lengua histórica dada. La anterior define el dominio de las raíces en la adquisición del lenguaje; la última, los parámetros que pueden modificarse para dar lugar a una raíz concreta, los límites a los que se somete una raíz particular. Dependiendo, entonces, de cómo se parametricen $[ \pm \mathrm{h}, \pm 1]$ y $\left[+\mathrm{P}_{i}\right]$, obtendremos la raíz específica de la lengua dada.

Para observar cómo trabaja nuestro sistema, veamos qué efectos se obtienen cuando aplicamos (5) al dominio semántico de la locución, de modo tal que $\mathrm{P}_{i}=\mathrm{L}$ (ocución). Como hemos tratado en profundidad en Hernández Arocha (2014, 2016a, 2016b), la diferencia esencial entre las raíces $\sqrt{ }$ dec- y $\sqrt{ }$ habl-, como verbos prototípicos de locución, radica en el hecho de que la primera (6) focaliza el argumento más incrustado de su estructura argumental, mientras que la segunda (7) focaliza el más prominente. En otras palabras: la raíz $\sqrt{ }$ dec- define la función que, tomando la intensión de un marco semántico locutivo, selecciona su argumento interno o jerárquicamente menos prominente; $\sqrt{h}$ abl-, por el contrario, selecciona el mismo marco, pero impulsará hacia la sintaxis explícita el argumento más prominente.

$$
\begin{aligned}
& \sqrt{ } \operatorname{dec}-:=\left\langle\left\langle i,\left\langle e_{[+\mathrm{h},-1]},\left\langle s, \mathrm{t}_{[+\mathrm{L}]}\right\rangle\right\rangle\right\rangle,\left\langle\bullet e_{[+\mathrm{h},-1]},\left\langle s, t_{[+\mathrm{L}]}\right\rangle\right\rangle\right\rangle \\
& \sqrt{ } \text { habl-: }:\left\langle\left\langle i,\left\langle e_{[-\mathrm{h},+1]},\left\langle\mathrm{s}, \mathrm{t}_{[+\mathrm{L}]}\right\rangle\right\rangle\right\rangle,\left\langle\bullet_{[-\mathrm{h},+1]},\left\langle s, t_{[+\mathrm{L}]}\right\rangle\right\rangle\right\rangle
\end{aligned}
$$

Hemos dicho que una raíz funciona como interfaz entre la cognición y la semántica lingüística, así como entre la semántica y la sintaxis. Ambas raíces, decy habl-, en tanto que verba dicendi, seleccionan el marco semántico de locución (8) e imponen restricciones sobre él. El marco puede parafrasearse, haciendo uso del modelo de Wotjak (2006), como sigue: 'presupuesto el hecho (SETTING) de que tanto un emisor $(x)$ como un receptor $(y)$ disponen de (НАв) un código lingüístico $(z)$ y que el emisor tiene además un mensaje $(w)$ que trasmitir, entonces ocurre (EVENT), que el emisor hace uso (OPER) del código para causar así que el código represente (REPR) su mensaje y el receptor disponga de un mensaje homólogo $\left(w^{\prime}\right)$, no idéntico, al que había codificado el emisor; como consecuencia (CONSEQ), el receptor dispone ya de un mensaje homólogo al verbalizado por el receptor'.

Marco semántico de LOCUCIóN

$$
\begin{gathered}
\lambda\left(x, \ldots, w^{\prime}\right) \lambda s . \\
\mathrm{P}_{l o c} \\
\left.\operatorname{ETHAB}(x \& y, z) \& \operatorname{HAB}(x, w)]_{\mathrm{ti}}\right] \operatorname{SETTING} \\
\operatorname{ET}\left[\left[\operatorname{HAB}\left(y, w^{\prime}\right)\right]_{\mathrm{ti}+1}\right] \operatorname{CONSEQ}
\end{gathered}
$$

El presente marco semántico de locución lo abstraeremos, por fines de claridad, como $\mathrm{P}_{l o c}$. El lector que no esté familiarizado con el modelo de Wotjak puede tomar como punto de partida el marco descrito en el modelo del Lexicón generativo 


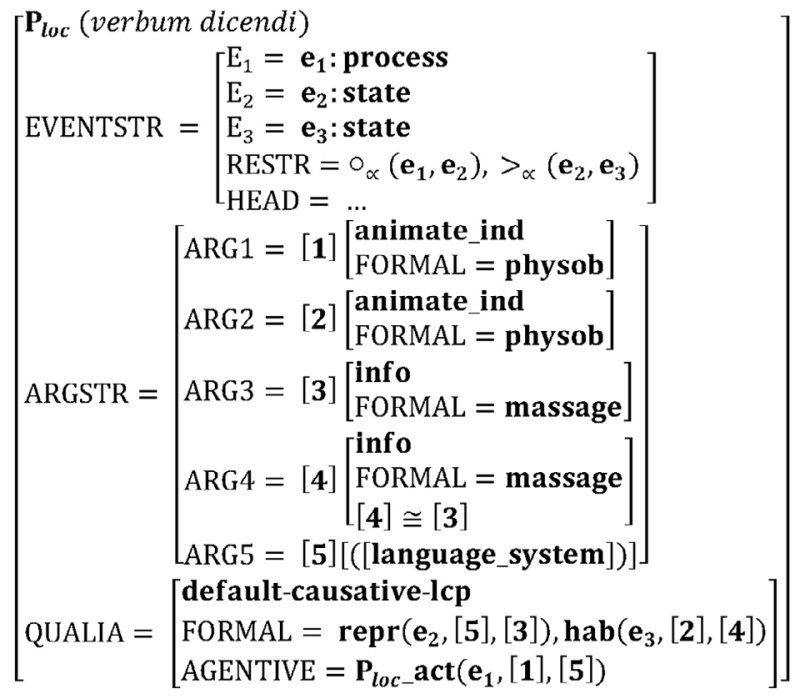

Fig. 6. Marco semántico de locución descrito de acuerdo con modelo del Lexicón generativo de Pustejovsky (1995).

de Pustejovsky (1995), ampliamente conocido, y que representamos en la figura 6 como variante meramente notacional de (8).

De acuerdo con lo mantenido hasta ahora, la raíz selecciona la intensión de $\mathrm{P}_{l o c}$ y le impone las condiciones correspondientes a la raíz. Pero llevemos a cabo la derivación paso a paso. Tomemos la raíz $\sqrt{ }$ dec-. La función de esta raíz -que, en la denominada "Escuela semántica de La Laguna», el profesor Morera ha dado en llamar «significación primaria»- se estructura de acuerdo a los límites impuestos por (6). La expresión lambda correspondiente a (6) es (9a). Esta expresión denota el hecho de que se precisa evaluar un índice, esto es, el conjunto de mundos, intervalos temporales y contextos posibles para los que el evento que consideramos LOCUción es el caso. Habiendo verificado cuál es tal índice, sabremos cuál es la intensión del predicado Locución, que hemos anotado $\mathrm{P}_{l o c}$. De este modo, aplicando al índice (i) la función de la raíz, podremos operar ya con la intensión ${ }^{\wedge}$ de $\mathrm{P}_{l o c}-$ no solo con su extensión ${ }^{\vee}-$. Así, la aplicación de la función al índice $(i)$ nos permitirá cancelar $\lambda i$ y pasar de (9a) a (9b). Ahora que estamos trabajando con la intensión de $\mathrm{P}_{l o c} \mathrm{y}$ no con su extensión, aplicamos el evento a la raíz, de modo tal que cancelamos $\lambda \mathrm{P}_{l o c}$ con $\mathrm{P}_{l o c}$ y pasamos de (9b) a (9c). Nótese que lo que estamos haciendo es, en el fondo, aplicar la función (6) a la intensión del evento cognitivo requerido (8) o, si se quiere, la plantilla equivalente que representamos en la figura 6 , para imponerle restricciones. En el momento en el que la raíz ya accede al evento que debe modificar, busca entonces el argumento más incrustado en la estructura lógica, esto es, $w^{\prime}$, y lo focaliza, aplicándole el operador $\bullet$. La representación (9c) se corresponde con una raíz léxica, de tipo $\langle e,\langle s, t\rangle\rangle$, que contiene ya todo su sentido cogni- 
tivo-enciclopédico y puede ser manipulada por la sintaxis explícita. Las computaciones llevadas a cabo hasta ahora se corresponden con lo que Hale / Keyser (2002) denominan «sintaxis-l(éxica)» o lo que Ramchand (2008) considera «sintaxis de la primera fase», con la única diferencia de que, en el caso de los autores citados, esta tarea la asume la sintaxis.

$$
\begin{aligned}
& \text { a. } \lambda i \lambda \mathrm{P}_{l o c} \lambda w^{\prime} \lambda x \lambda s . \exists(y, \ldots, w)\left[{ }^{\vee} \mathrm{P}_{l o c}\left(x, \ldots, \bullet w^{\prime}\right)\right](s)\left(\mathrm{P}_{l o c}\right)(i) \\
& \text { b. } \lambda \mathrm{P}_{l o c} \lambda w^{\prime} \lambda x \lambda s . \exists(y, \ldots, w)\left[{ }^{\wedge} \mathrm{P}_{l o c}\left(x, \ldots, \bullet w^{\prime}\right)\right](s)\left(\mathrm{P}_{l o c}\right) \\
& \text { c. }{ }^{*} \lambda w^{\prime} \lambda s . \exists(x, y, \ldots, w)\left[{ }^{\wedge} \mathrm{P}_{l o c}\left(x, \ldots, \bullet w^{\prime}\right)\right](s) \\
& \text { d. } \lambda w^{\prime} \lambda x \lambda s . \exists(y, \ldots, w)\left[{ }^{\wedge} \mathrm{P}_{l o c}\left(x, \ldots, \bullet w^{\prime}\right)\right](s)
\end{aligned}
$$

Debemos advertir aquí un problema importante. Tal y como han señalado Van Valin / La Polla (1997), Wunderlich (2012), entre otros, los argumentos que asumen los bordes de un evento se proyectan universalmente a la sintaxis para recibir caso estructural, esto es, nominativo y acusativo o ergativo y absolutivo, dependiendo de la tipología lingüística ${ }^{5}$. Para este último autor, dada una cadena argumental abstraída mediante un operador lambda, por ejemplo $\lambda\left(x_{1}, \ldots, x_{n}\right)$, los argumentos $x_{1}$ y $x_{n}$ se preyectarían como nominativo y acusativo, respectivamente, al tiempo que la subcadena $\left(x_{2}, \ldots, x_{i}, \ldots, x_{n-1}\right)$ quedaría relegada o bien a casos léxicos como el dativo ético, para algún $x_{i}$ en la cadena, o bien a su verbalización como adjuntos o circunstantes.

Siendo así las cosas, cabe advertir que este es un principio aplicable al nivel de la llamada "forma semántica» (FS), es decir, a la expresión semántica ya categorizada y determinada por la raíz, lista para ser manipulada por la sintaxis explícita, pero no al nivel de la raíz o, como habíamos mencionado antes, de su «significación primaria». Dado que, tal y como está definida, una raíz (5) es opaca para más de un argumento y sabemos que las formas semánticas pueden ser impersonales, intransitivas (agentivas o inergativas), transitivas o ditransitivas, es necesario definir cómo se manifiesta este principio a nivel de la raíz. Creemos que una primera tentativa podría definirse como sigue, donde la letra griega representa una metavariable para argumentos y el subíndice el tipo lógico al que esta pertenece:

Asimetría realizativa

Todo argumento eventivo $\alpha_{e}$, vinculado con el operador lambda a un marco semántico, se ve cuantificado existencialmente por la raíz, a no ser que: (a) esté focalizado (esté bajo el dominio de •), (b) se encuentre en el dominio estrictamente local de un argumento focalizado o (c) no haya ningún argumento $\beta_{e}$ que sea más prominente que $\alpha_{e}$.

5 Por razones de simplicidad, nos referiremos a continuación al sujeto y complemento directo de una oración de una lengua sin casos con la misma terminología, nominativo y acusativo, respectivamente. 
De esta forma, podremos definir concretamente los cinco tipos diatéticos de predicados (verbales), proyectables ahora desde la raíz:
a. $\left.V_{\text {intransitiva_ergativa }}:=\left\langle\left\langle i,\left\langle e[-\mathrm{h},-1],\left\langle s, t_{\left[+\mathrm{P}_{i}\right]}\right\rangle\right\rangle\right\rangle,\left\langle\bullet e_{[-\mathrm{h},-1]},\left\langle s, t_{\left[+\mathrm{P}_{i}\right]}\right]\right\rangle\right\rangle\right\rangle$
b. $\left.\left.V_{\text {intransitiva_agentiva: }}=\left\langle\left\langle i,\left\langle e_{[-\mathrm{h},+1]},\left\langle s, t_{\left[+\mathrm{P}_{i}\right]}\right]\right\rangle\right\rangle\right\rangle,\left\langle\bullet e_{[-\mathrm{h},+1]},\left\langle s, t_{\left[+\mathrm{P}_{i}\right.}\right]\right\rangle\right\rangle\right\rangle$
c. $V_{\text {transitiva }}:=\left\langle\left\langle i,\left\langle e_{[+\mathrm{h},-1]},\left\langle s, t_{\left[+\mathrm{P}_{i}\right]}\right\rangle\right\rangle\right\rangle,\left\langle\bullet e_{[+\mathrm{h},-1]},\left\langle s, t_{\left[+\mathrm{P}_{i}\right]}\right\rangle\right\rangle\right\rangle$
d. $V_{\text {ditransitiva }}:=\left\langle\left\langle i,\left\langle e_{[+\mathrm{h},+1]},\left\langle s, t_{\left[+\mathrm{P}_{i}\right]}\right\rangle\right\rangle\right\rangle,\left\langle\bullet e_{[+\mathrm{h},+1]},\left\langle s, t_{\left[+\mathrm{P}_{i}\right]}\right\rangle\right\rangle\right\rangle$
e. $V_{\text {impersonal }}:=\left\langle\left\langle i,\left\langle e_{[-\mathrm{h},-1]},\left\langle s, t_{\left[+\mathrm{P}_{i}\right]}\right\rangle\right\rangle\right\rangle,\left\langle e_{[-\mathrm{h},-1]},\left\langle\bullet s, t_{\left[+\mathrm{P}_{i}\right]}\right\rangle\right\rangle\right\rangle$

En el primer caso (11a) tenemos raíces que se manifestarán en construcciones intransitivas, dado que seleccionan marcos semánticos monoargumentales, sin complejidad predicativa y, por lo tanto, carentes de agentividad. Al existir un único argumento, la focalización es trivial, pero su exteriorización sintáctica (el efecto colateral de •) necesaria. Es el caso de raíces como la del verbo ir. En el segundo caso (11b), la raíz selecciona un marco semántico complejo, evocador de más de un argumento, y focaliza su variable argumental más prominente, que proyecta hacia la sintaxis, bloqueando existencialmente el resto, dado que el marco no posee ningún otro argumento en el dominio local del argumento focalizado al que no le suceda otro más incrustado. Estamos, pues, ante raíces como las que subyacen al verbo español hablar o inglés speak. En el tercer caso (11c), la raíz selecciona de nuevo un marco semántico elaborado, pero focaliza y proyecta a la sintaxis su argumento menos prominente o más incrustado. Aplicada al marco de la locución, estaríamos ante raíces de verbos como decir en español o say en inglés.

Adviértase, sin embargo, que, dado que la raíz focaliza el argumento más incrustado, cuantificará existencialmente cualquier otra variable argumental presente en el marco, conforme a lo que hemos dicho supra acerca de los rasgos atencionales o focalizadores (B). La aplicación de la raíz generará, por tanto, un verbo intransitivo, de tipo $\langle e,\langle s, t\rangle\rangle$. Este resultado produce defectivamente agramaticalidad, de modo que no habrá forma, entonces, de introducir un nuevo argumento para formar las construcciones transitivas en las que tales verba dicendi suelen aparecer. Este es, de hecho, el estadio que habíamos alcanzado en (9c). No obstante, si elevamos (10) a la categoría de principio al que toda raíz se deba someter, ocurrirá entonces lo siguiente. Ya que ni la notación lineal de la lógica de predicados de primer orden que define (8) ni la plantilla léxica homóloga que tenemos en la figura 6 nos permiten captar con claridad la denominada "geometría del evento», consideremos entonces la figura 7, en la que segmentamos los intervalos de verificación para cada predicado, así como su estructura arbórea. Vemos, entonces, que la raíz, al seleccionar el evento del marco Locución, esto es, $\sqrt{ }\left(\operatorname{EVENT}\left(\mathrm{P}_{\text {loc }}\right)\right)$, escanea el nivel más bajo o de mayor incrustación, a saber, el nivel $e$ en la figura 7 , y focaliza su argumento más incrustado, es decir, $w$, vinculándolo al predicado resultante mediante el operador lambda y cuantificando existencialmente el resto de argumen- 
tos $(x, z, y, w)$. Ahora vemos que la variable $w$ ' no presenta ninguna otra incrustada en su dominio local, al ser ella misma la que concluye el evento, pero sí existe otra variable que satisfaga la propiedad de no tener ningún otro argumento más prominente, a saber, $x$. De este modo, (10) obligará al argumento $x$ a abstraerse mediante el operador lambda, de modo tal que quede habilitado para proyectarse como argumento externo o más prominente en la sintaxis explícita. Esto nos permite trascender nuestro estadio de agramaticalidad (9c) hasta alcanzar el predicado transitivo esperado (9d), de tipo $\langle e,\langle e,\langle s, t\rangle\rangle\rangle$. En estos casos, si se inserta un dativo, será ético y su eliminación no producirá agramaticalidad ( $(s e)$ lo dije).

De ser así las cosas, ¿qué ocurriría con raíces que focalicen un argumento que presenta otra variable más incrustada y otra menos incrustada? Estaríamos entonces ante instanciaciones ditransitivas de una raíz, como (11d), que proyectarían obligatoriamente un dativo a la sintaxis explícita, pero se verían forzadas a proyectar también un nominativo y un acusativo, dado que ambos satisfarían las cláusulas (b) y (c) de (10). En español no existen ejemplos léxicos de tales raíces en el dominio de la locución, pero podría tomarse la raíz del verbo inglés tell como ejemplo (cf. I told - you that, ${ }^{*} I$ told $\varnothing$ that, I told that to $\bullet$ you). Para encontrar un ejemplo en español bastaría con cambiar el dominio léxico, por ejemplo, escogiendo el dominio posesivo del verbo dar $\left(\bullet\right.$ le doy el regalo, ${ }^{*} \varnothing$ doy el regalo).

Hay, con todo, un aspecto relevante que comentar a propósito de este tipo de raíces. Si la instrucción que sigue la raíz es la de seleccionar aquella variable que tenga al menos otra variable más incrustada y otra más prominente, y tenemos un marco como el representado en la figura 7, ¿cómo reconoce la raíz que es y el argumento que debe focalizar y no $z$ o $w$, que satisfacen también la misma restricción? Parece evidente que, de acuerdo con (10), estas tres variables son candidatas igualmente válidas y, por ello, o focaliza la raíz una de ellas de forma aleatoria o no sabrá cuál focalizar. Pero, en las construcciones ditransitivas, es siempre el BENEFICIARIO / RECEPTOR / PERCEPTOR el argumento que debe ser focalizado y recibir obligatoriamente el caso estructural dativo, no cualquier otro. En nuestro marco semántico, es precisamente $y$ el único candidato posible, dado que el resto produciría agramaticalidad. De ser así, la raíz sobregeneraría, produciendo más construcciones de las que la lengua permite.

De nuevo, es el principio (10), en coordinación con las restricciones del operador, el que resuelve la ambigüedad conforme a la cláusula (B). Dado que, para que el dativo $\alpha_{e}$ presente un argumento más incrustado $\beta_{e}$, que se manifieste estructuralmente en caso acusativo, $\beta_{e}$ no puede estar situado en ninguna otra posición que no sea el dominio local de $\alpha_{e}$ pero tampoco por encima de algún otro argumento $\gamma_{e}$, entonces $\beta_{e}$ debe ser el último argumento de la jerarquía. Adviértase que, con un evento con una estructura argumental de cinco variables $\left(x_{1}, \ldots, x_{i}, \ldots, x_{5}\right)$, si $x_{i}$ es $x 3$ y recibe la focalización al encontrarse en una posición intermedia, entonces $x 4$ se cuantifica existencialmente y no podrá proyectarse hacia la sintaxis explícita como acusativo, dado que no se encuentra situado en el contorno final del evento. Como el único argumento que satisface las restricciones que se le imponen a $\beta_{e}$ es $w^{\prime}$, entonces, $\alpha_{e}$ deberá ser $y$. 


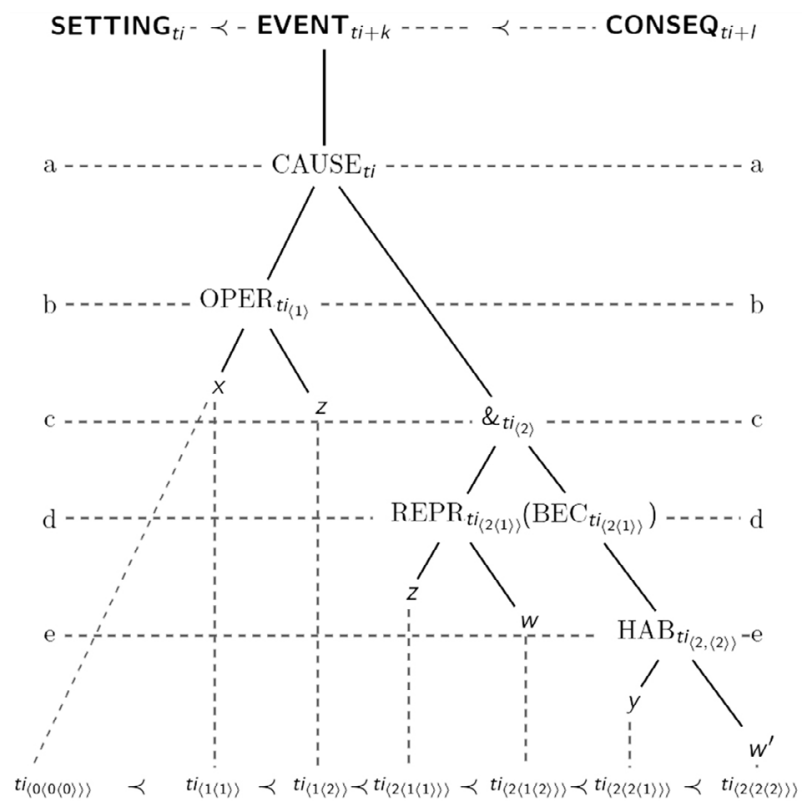

Fig. 7. Geometría del marco semántico de locución.

De nuevo, creemos que tenemos un argumento sólido en favor de la teoría de raíz que aquí esbozamos. Pero no hemos agotado aún todas las posibilidades. Por último, tendríamos el caso en el que, como ocurre con los verbos ergativos, disponemos de un predicado monomembre que, a diferencia de ellos, no presenta focalizado su argumento predicativo, sino su argumento situacional externo $(s)$, el argumento llamado "davidsoniano» en honor a su introductor, el filósofo estadounidense Donald Davidson, de forma que queda bloqueado el argumento predicativo y se realiza únicamente la situación. En este caso, tenemos dos posibilidades: en las lenguas de sujeto obligatorio este no se realiza, sino que se coloca un expletivo para rellenar la posición obligatoria del sujeto (it rains [ingl.], es regnet [al.], il pleut [fr.], etc.); por el contrario, en las lenguas denominadas "pro-drop", no es necesario saturar tal posición, de forma que se prescinde del expletivo (['ocurre $s$ (es decir, que):'] llueve [esp.], piove [it.], etc.).

Antes de pasar a aspectos específicos de nuestro análisis, nótese que lo que conseguimos mediante las manifestaciones argumentales (11) de una raíz abstracta (5) es crear sensibilidad a la jerarquía o estructura lógica que vemos en la fig. 7. Por tanto, los tres tipos de incidencia predicativa de la raíz que proponía Levinson en la figura 4 pueden ser derivados, sin mayor complicación, de algunos de los dominios de incidencia que las diferentes manifestaciones categoriales en (11) posibilitan. También la llamada "alternancia de la manera y el estado resultante» (Levin / Rappaport 2013, Hernández Socas 2020) puede ser predicha atendiendo al grado de incrustación argumental de un evento y las restricciones que una raíz 
léxica dada cierne sobre él. Llegados a este punto, parece que, sometido el formato abstracto de raíz (5) a un principio general de realización (10), hemos alcanzado un grado de nitidez en el dominio de estudio suficiente como para permitirnos avanzar con una teoría robusta, sin temor a que el sistema sobregenere cuando se cambie de clase léxica.

Resumamos, entonces, lo expuesto hasta ahora: la tarea que lleva a cabo la raíz $\sqrt{ }$ dec-, expuesta en (6), es seleccionar la intensión del marco de LOCución, expuesto en (8) -y representado como plantilla léxica en la figura 6 o como diagrama arbóreo en la figura 7- y focalizar su argumento más incrustado, de modo que la función nos devuelve el evento focalizado decir, que observamos en (12) o su plantilla homóloga, que vemos en la figura 8.

Forma semántica del predicado (verbal) decir

$$
\lambda w^{\prime} \lambda x \lambda s .\left[\operatorname{decir}\left(x, \bullet w^{\prime}\right)\right](s)
$$

$$
\lambda w^{\prime} \lambda x \lambda \text { s. } \exists(y, \ldots, w)
$$

$\left[[\operatorname{HAB}(x \& y, z) \& \operatorname{HAB}(x, w)]_{\mathrm{t}}\right]$ SETTING

$\left.\operatorname{ET}\left[\left[\operatorname{OPER}(x, z) \& \operatorname{CAUSE}\left(x, \operatorname{REPR}_{\mathrm{ext}}(z, w) \& \operatorname{HAB}\left(y, \bullet w^{\prime}\right)\right)\right)\right]_{\mathrm{ti}+\mathrm{k}}\right]_{\operatorname{EVENT}}(s)$

$$
\operatorname{ET}\left[\left[\operatorname{HAB}\left(y, \bullet w^{\prime}\right)\right]_{\mathrm{ti+}+1}\right] \text { CONSEQ }
$$

En la forma semántica (12), vemos ya que el predicado generado por la raíz requiere dos argumentos, el EMISOR $(x)$ y el MENSAJE $\left(w^{\prime}\right)$, donde el segundo está focalizado, de forma que produce un accomplishment, no una actividad, y relega el resto de argumentos al ámbito de la presuposición semántica. En el modelo del lexicón generativo (fig. 8), observamos que los argumentos [1] y [4] presentan estatus estructural, al tiempo que los argumentos [2], [3] y [5] se convierten en default arguments, esto es, en argumentos presupuestos o consabidos. Pustejovsky, a diferencia de la semántica cognitiva, no contempla la focalización como componente de las plantillas léxicas, pero sí determina el llamado HEAD, es decir, el subevento que debe ser proyectado obligatoriamente a la sintaxis y que representa el núcleo informativo del evento. Como en el subevento nuclear ez el único argumento estructural es [4], el MENSAJE, este representará su núcleo informativo, que es lo mismo que decir que representa su argumento focalizado. Por ello podemos decir que la raíz (6) toma la plantilla de la figura 6 , como marco semántico de Locución, y nos devuelve el evento de la figura 8 , como predicado idiosincrásico del español.

En este punto podemos generalizar, entonces, que toda raíz (5) es una función de tipo 13, es decir, una función que selecciona marcos y devuelve eventos. Dicho de otro modo, como el significado de una raíz ha dado en llamarse «significación primaria» (SP) (Morera 2007), los contenidos cognitivos «marcos semánticos o frames» (Wotjak 2006) y la semántica de un evento una "forma semántica» (FS) (Bierwisch 2006; Wunderlich 2012), entonces podemos concluir que las significaciones primarias seleccionan marcos y devuelven formas semánticas, hábiles para ser manipuladas por la sintaxis. 


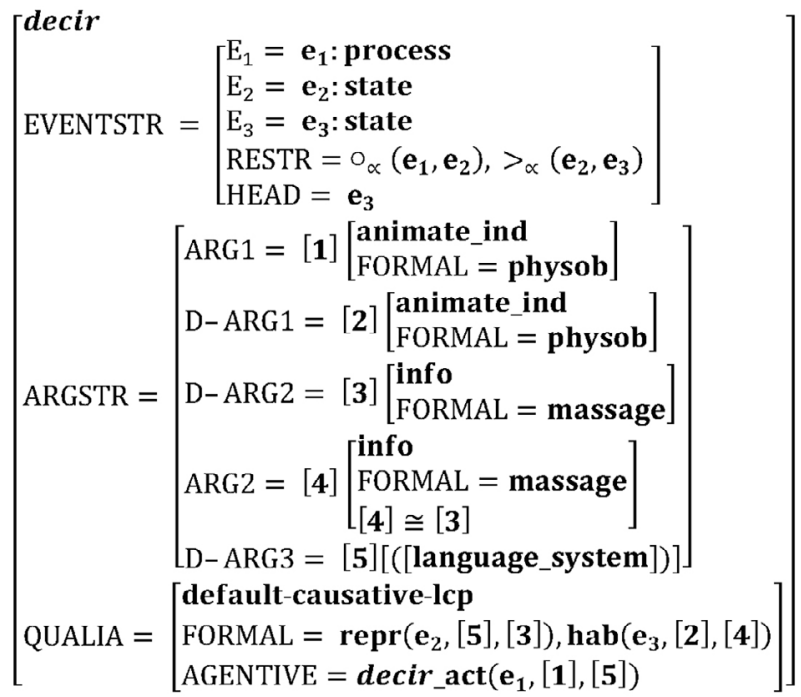

Fig. 8. Plantilla léxica del predicado (verbal) decir.

$$
\mathrm{SP} \sqrt{ }(\mathrm{FRAME})=\mathrm{FS} \text {. }
$$

Veamos ahora qué ocurre con la raíz $\sqrt{ }$ habl-, que habíamos descrito en (7), con su expresión lambda correspondiente en (14a). Una vez aplicado el índice al marco en (14b) y la intensión del marco (8) a la raíz (7), que focaliza su argumento externo, obtenemos (14c), que describimos con más exhaustividad en (15).

$$
\begin{aligned}
& \text { a. } \lambda i \lambda \mathrm{P}_{l o c} \lambda x \lambda s . \exists\left(y, \ldots, w^{\prime}\right)\left[{ }^{\vee} \mathrm{P}_{l o c}\left(\bullet x, \ldots, w^{\prime}\right)\right](s)\left(\mathrm{P}_{l o c}\right)(i) \\
& \text { b. } \lambda \mathrm{P}_{l o c} \lambda x \lambda s . \exists\left(y, \ldots, w^{\prime}\right)\left[{ }^{\wedge} \mathrm{P}_{l o c}\left(\bullet x, \ldots, w^{\prime}\right)\right](s)\left(\mathrm{P}_{l o c}\right) \\
& \text { c. } \lambda x \lambda s . \exists\left(y, \ldots, w^{\prime}\right)\left[{ }^{\wedge} \mathrm{P}_{l o c}\left(\bullet x, \ldots, w^{\prime}\right)\right](s)
\end{aligned}
$$

En (15), como en (12), el primitivo hablar'representa una abstracción notacional de lo que denota intensionalmente su contenido, que elaboramos bajo la llave.

$$
\text { Forma semántica del predicado (verbal) hablar }
$$

$\lambda x \lambda$ s. $\left[\operatorname{hablar}^{\prime}(\cdot x)\right](s)$

$$
\lambda x \lambda \text { s. } \exists\left(y, \ldots, w^{\prime}\right)
$$

$\left[[\mathrm{HAB}(\bullet x \& y, z) \& \operatorname{HAB}(x, w)]_{\mathrm{ti}}\right]$ SETTING

$\left.\operatorname{ET}\left[\left[\operatorname{OPER}(\bullet x, z) \& \operatorname{CAUSE}\left(\bullet x, \operatorname{REPR}_{\mathrm{ext}}(z, w) \& \operatorname{HAB}\left(y, w^{\prime}\right)\right)\right)\right]_{\mathrm{ti}+\mathrm{k}}\right]_{\operatorname{EVENT}}(s)$ $\operatorname{ET}\left[\left[\mathrm{HAB}\left(y, w^{\prime}\right)\right]_{\mathrm{ti}+1}\right]$ CONSEQ 


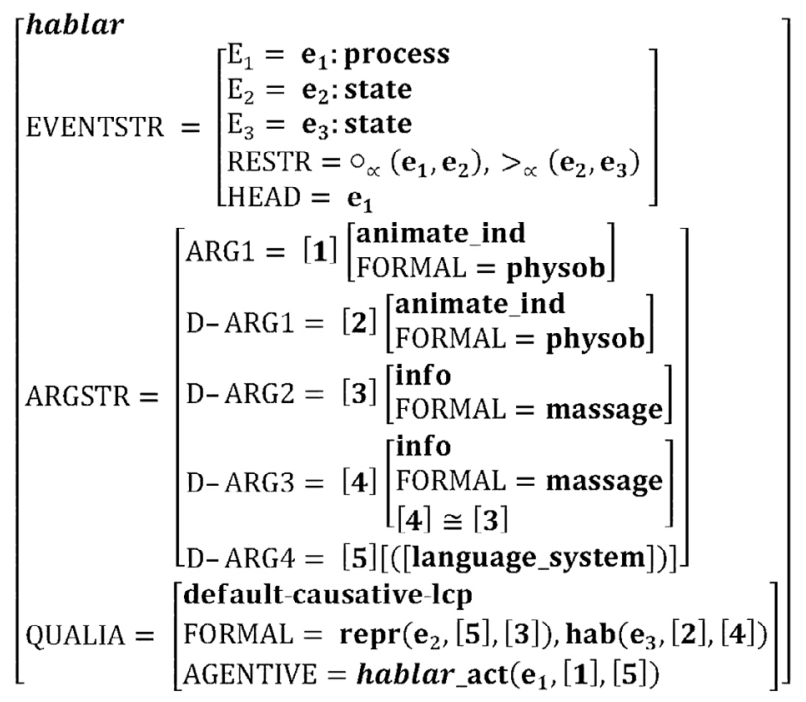

Fig. 9. Plantilla léxica del predicado (verbal) hablar.

Como en el caso anterior, (15) constituye una representación semántica enteramente homóloga a la que se presenta en la figura 9. En esta última, el subevento nuclear es $\mathbf{e}_{\mathbf{1}}$, en el que el único argumento estructural (ARG) es [1], equivalente a $x$ en (15), dado que el argumento restante en $\mathbf{e}_{\mathbf{1}}$, a saber, [5], presenta estatus de default argument (D-ARG). El efecto de la prominencia o exterioridad del único argumento focalizado del que se predica el evento complejo será el de evocar agentividad y dinamicidad, con ausencia de telicidad. El predicado hablar será, por tanto, agentivo, dinámico y atélico, esto es, una actividad, en la conocida clasificación de Vendler, al tiempo que el predicado decir será agentivo y dinámico, pero télico, esto es, un accomplishment o realización. El contraste puede observarse en (16) y (17):

$$
\begin{aligned}
& \text { a. Pedro (le) habla }\{\text { rápido/*que venga\}. } \\
& \text { b. Pedro (le) habla todo el tiempo. } \\
& \text { (LOCUCIÓN } \mathrm{HEAD}_{\mathrm{H}=\mathbf{e}_{\mathbf{1}}}=\text { activity) [+ durativo] }
\end{aligned}
$$

a. Pedro (le) dice $\left\{{ }^{*}\right.$ rápido/que venga\}.

b. Pedro (le) dice que venga todo el tiempo.

(LOCUCIÓN $\mathrm{HEAD}_{\mathrm{HE}} \mathrm{e}_{3}=$ accomplishment) [+ iterativo]

Por todo lo expuesto, vemos que las raíces, cargadas únicamente con contenido focalizador, desencadenan diversos efectos colaterales al interactuar con el marco semántico que seleccionan. Por un lado, determinan de forma decisiva la valencia sintáctica y semántica del predicado resultante, que anotamos en la figura 9 como arg y d-arg, respectivamente. Por otro lado, permite predecir el aspecto léxico 
del predicado: se considerará atélico todo predicado que nuclearice su primer subevento, esto es, si focaliza su argumento más prominente, al tiempo que se considerará télico todo aquel que focalice el último subintervalo, como consecuencia de haber focalizado la variable más incrustada del marco.

Pero la focalización desencadena, además, otros efectos que hemos estudiado con más detenimiento en Hernández Arocha (2016b) y retomaremos ahora para ejemplificar solo dos manifestaciones prototípicas, aunque no canónicas, de este tipo de verbos. Hemos visto que la focalización de un argumento repercute en la nuclearización del subevento que lo alberga. En la figura 7 , se puede observar que el predicado que contiene la primera manifestación de la variable más prominente, esto es, OPER, contiene también otra variable $z$, que denota el CóDIGO LINGüístico. En la figura correspondiente 9, el subevento e1 contiene, además del hablante focalizado [1], también el código o sistema lingüístico [5]. Es natural que, si la focalización de un argumento nucleariza el subevento que lo alberga, la nuclerización de tal subevento irradiará su focalización a cualquier otro argumento que se sitúe bajo su dominio. Por lo tanto, la raíz que postulamos estipulará que, si se focaliza el argumento externo, entonces el código, que se encuentra en su dominio local, será irradiado con su focalización y podrá ser expresable. Si, por el contrario, se focaliza el argumento interno, la variable menos prominente, el código, no recibirá focalización, de modo que la semántica se colapsará, como vemos en (18a). Ocurre, entonces, que un verbo prototípicamente intransitivo pasa a realizarse como transitivo como efecto colateral de la focalización, al tiempo que un verbo transitivo, desprovisto de la focalización adecuada, desencadena una restricción en el complemento, aunque este participe de una solidaridad léxica de «selección» con la raíz, como diría Coseriu.

a. Marcos $\{$ habla/*dice\} francés.

b. Marcos habla \{boberías / sandeces / *historias / * poemas,...\}.

Así como un verbo transitivo como decir puede producir agramaticalidad con un objeto que selecciona semánticamente, aunque parezca contradictorio, puede ocurrir, también, que un verbo intransitivo permita un cambio de diátesis, convirtiéndose en transitivo, si tal cambio es acorde con la focalización de la raíz. Así, si el complemento ańadido predica una propiedad del argumento focalizado se habilita la transitivización, al tiempo que, si no lo hace, se bloquea, como vemos en (18b).

Como vemos, la raíz desempeña un papel considerablemente más importante en la combinatoria sintáctica de lo que con frecuencia se asume, subordinando a su arbitrio incluso las relaciones selectivas. No podemos ahondar más en este problema por razones de espacio, pero remito a Hernández Arocha (2016b) para una gama considerablemente más amplia de restricciones. Pasemos ahora a analizar cuál es el papel que desempeńa la raíz en la conformación morfológica de la familia léxica. 


\section{LA RAÍZ Y LAS FAMILIAS DE PALABRAS}

Cualquier investigador que se haya adentrado en el estudio de familias léxicas se habrá percatado de un fenómeno que ya habían puesto de manifiesto numerosos investigadores en campos semánticos: las familias léxicas están llenas de huecos o lagunas, como observamos en el fragmento ilustrativo -y escogido al azar- de la familia de palabras decir (figura 10). Lo que nos interesa de esta figura y sobre lo que queremos llamar la atención no es, precisamente, lo que contiene, que ha sido analizado en profundidad en la referencia citada, sino lo que omite o excluye. Considérese que el fragmento expuesto, con las 32 unidades léxicas que se observan, representa el 12,5\% de la familia léxica dec- (256 unidades), una de entre las 7 más numerosas del español. Este reducido porcentaje de la abrumadoramente compleja familia dec-basta para advertir un hecho importante. De ese escueto subconjunto, solo contamos con un $27,3 \%$ de las posibilidades léxicas realizadas, ya que este fragmento, con sus 9 bases, multiplicadas por 12 sufijos más 1 proceso de nominalización, nos habilita 117 posibilidades. ¿Qué le ocurrió al 72,7\% restante?

Es importante destacar en este punto que lo que queremos someter a revisión aquí no es tanto el conjunto de restricciones locales que afectaron individualmente a algunas unidades léxicas, sobre las que existe un gran número de trabajos particulares que en parte hemos discutido e, incluso, reseñado en otros lugares (Hernández Arocha 2013, 2014, 2016a, b), sino si hay algún patrón general que inhabilitó algunas casillas y activó otras. En resumen: nos interesamos especialmente por lo que le ocurrió a la familia, no solo a las palabras concretas.

Con frecuencia, las razones que se arguyen para explicar estas casillas vacías se centran en restricciones locales, generalizables acaso como restricciones morfológicas de procedimientos derivativos, como las siguientes:

a. Irrelevancia designativa para crear o importar las unidades.

b. Restricciones en la productividad de los sufijos.

Del primer argumento, poco podemos decir aquí. En Hernández Arocha (2014) demostramos que (19a) suele ser una causa de relevancia en la pérdida léxica únicamente cuando el término competidor desde el punto de vista designativo, que aboca la unidad léxica concurrente a la desaparición, está morfológicamente menos recargado (ha sufrido menos procesos derivativos) que el término que finalmente desaparece. Pero, salvo en estos casos, (19a) parece ser un dominio arduo para la investigación. Concentrémonos, pues, en (19b).

Con respecto a las restricciones estructurales en la productividad de los sufijos, es decir, con respecto a las restricciones que no derivan de fenómenos de interfaz (con la cognición, fonología, etc.), suele atribuírseles, de nuevo, dos causas mayores:

a. La categoría base de la derivación.

b. El aspecto léxico de la base derivativa. 


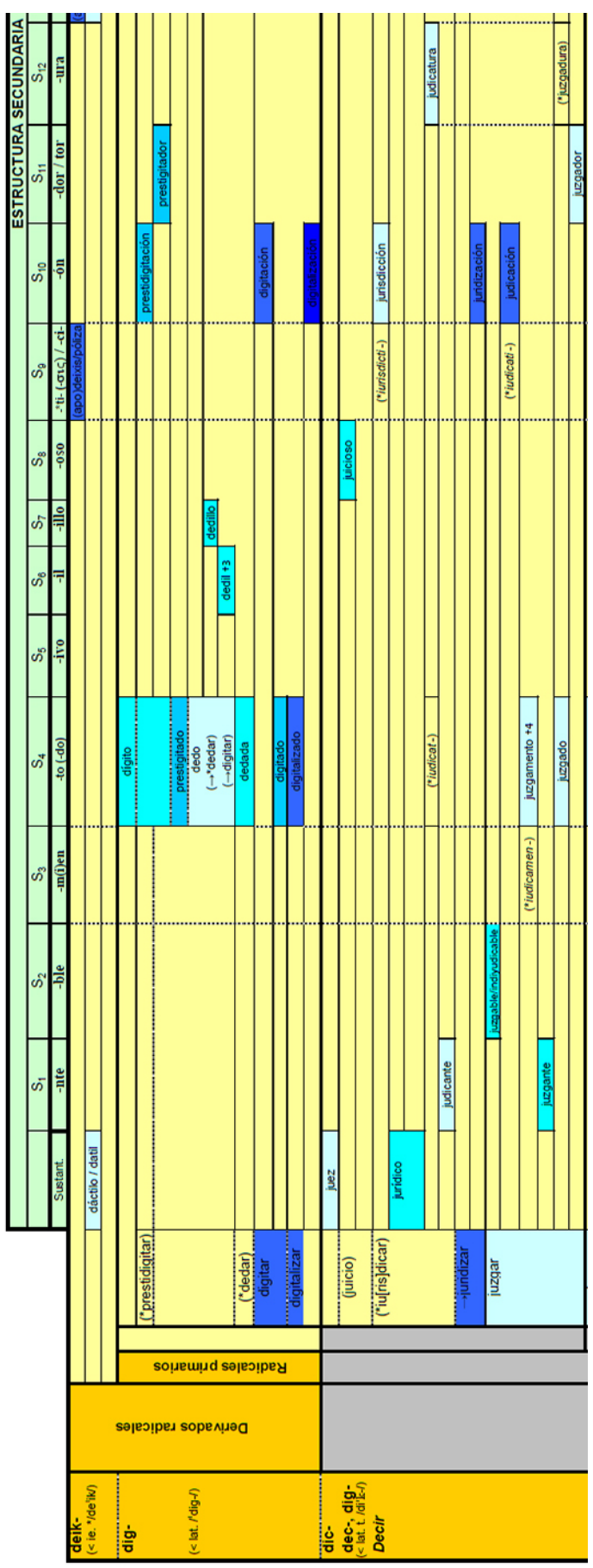

Fig. 10. Fragmento (12,5\%) de la familia de palabras decir (Hernández Arocha 2014). 
Téngase en cuenta que, en un modelo distribuido, en el que las raíces no están categorizadas, la productividad de la derivación dependerá de la estructura sintáctica. Un sufijo nominalizador deverbal podrá ser aplicado, entonces, si la raíz se inserta en un contorno verbal y solo bajo esta condición. Por lo tanto, el aspecto determinante de la productividad afijal sería, de acuerdo con modelos distribuidos como el exosquelético (Borer 2014) y los restantes estudiados en 2, la sintaxis. Es más, dado que en este tipo de aproximaciones, las raíces tampoco están provistas de aspecto léxico, sería también la sintaxis el componente responsable de esta interpretación eventiva, con lo que la causa (20b) dependería también crucialmente de la sintaxis. En consecuencia, las raíces no desempeñarían ningún papel relevante en la morfología productiva y la pregunta sobre si le ocurrió algo a la familia estaría mal formulada, dado que, si ocurrió algo, entonces les ocurrió a las unidades léxicas y en la sintaxis. Con todo, en adelante demostraremos la hipótesis de que otra aproximación es posible.

\subsection{LAS RAÍCES Y LA PREFIJACIÓN}

Veamos ahora qué consecuencias tiene el modelo semántico de raíz que hemos esbozado en los apartados anteriores y si, por el contrario a lo estipulado en los modelos distribuidos, la raíz puede conformar un núcleo decisivo en la productividad de la derivación. Partiremos, pues, de las raíces (6) y (7), teniendo en cuenta que tanto la valencia como la aspectualidad no son propiedades intrínsecas de la raíz -coincidiendo aquí con los modelos distribuidos-, sino efectos colaterales de su interactuación con la estructura conceptual y sintáctica.

Como hemos visto a propósito de la raíz hammer en la propuesta distribuida de Acedo-Matellán / Mateu, las raíces, carentes de toda estructura interna, pueden insertarse en cualquier posición, recibiendo, por tanto, una lectura atélica y télica. La pregunta que se nos plantea ahora es ¿por qué, si es la sintaxis la que le confiere categoría y aspecto a la raíz, encontramos tantas casillas vacías en la figura 10? ¿Por qué ocurre esto, si los dos aspectos decisivos para la saturación de las casillas, esto es, (20a) y (20b), están controlados únicamente por la sintaxis y esta representa una función recursivamente enumerable o, en otras palabras, la garantía por antonomasia de la productividad? Si la respuesta a estas preguntas es una supuesta contingencia generativa guiada por (19a), esto es, por las necesidades comunicativas del hablante o comunidad de hablantes, entonces deberíamos esperar que las casillas vacías no respondan a ninguna causa más allá de la decisión arbitraria del hablante de introducir una raíz en un contexto y no en otro y, consecuentemente, es de esperar que las casillas vacías no muestren ningún patrón regular.

Sin embargo, si observamos la tabla 2, donde los verbos hablar y decir están distribuidos asimétricamente con respecto al procedimiento derivativo, ¿por qué no ha ocurrido que la raíz $\sqrt{ }$ habl- haya asumido circunstancialmente el contorno sin- 
táctico de $\sqrt{ }$ dec- y haya permitido así, al menos, algunos derivados prefijales? ¿Por qué observamos una distribución privativa regular a favor de decir?6.

\begin{tabular}{ccc}
\hline \multicolumn{3}{c}{ TABLA 2. RESTRICCIONES EN LA PREFIJACIÓN } \\
\hline & DECIR & HABLAR \\
\hline re- & $\checkmark$ & $X$ \\
\hline des- & $\checkmark$ & $X$ \\
\hline pre- & $\checkmark$ & $X$ \\
\hline contra- & $\checkmark$ & $\times$ \\
\hline
\end{tabular}

Una respuesta habitual suele ser, como decimos, obviar lo dicho y apelar a la aspectualidad. La telicidad habilitaría la primera columna y su carencia deshabilitaría la segunda. Desde este punto de vista, la prefijación controla la productividad y las raíces se reducen a aportar referencia y a solventar los problemas de autonomía realizativa de los afijos. Pero adviértase que esta aproximación solo puede ostentar, a lo sumo, un estatus descriptivo para un conjunto amplio de datos, pero nunca explicativo: si decir es télico por definición, ¿qué explica sus usos atélicos como la retórica es el arte del buen decir \{durante horas/*en una hora\}? Por otro lado, si hablar es atélico, ¿de dónde procede el uso no tengo tiempo, tenemos que hablarlo todo en cinco minutos? Y, si a mbos verbos pueden ser télicos o atélicos, ¿por qué se escinde la tabla 1 de un modo tan regular? Aun cuando no se distribuyera privativamente, ¿qué es lo que hace de un verbo télico el que no pueda ser atélico o viceversa, si ambos denotan el mismo marco? Si ambos evocan el marco Locución y en ambos casos existe un subevento que es el final de la acción (el subevento en el que el receptor recibe el mensaje) y si, además, ambos verbos son susceptibles de recibir un complemento indirecto que verbalice tal subevento final, ¿por qué se escinde la telicidad en tantos casos? ¿Qué sabemos más de un verbo diciendo que, aun pudiendo ser atélico, es télico o afirmando que, siendo insensible a este rasgo, suele ser más télico que atélico o viceversa? Efectivamente, descripciones de este tipo no dejan de ser análisis ad hoc, que no se mantienen tras un análisis minucioso de los datos $\mathrm{y}$, aunque se mantuviesen, no comprenderíamos mejor el problema.

Nosotros no negamos que la prefijación sea sensitiva a la telicidad, pero pensamos que esta regularidad proviene de la raíz, no de la prefijación. Al focalizar el argumento más incrustado de la estructura conceptual que modifica, $\sqrt{ }$ dec-predetermina que el estado más prominente en la eventualidad sea el del borde final del evento (e3), haciendo así prevalecer la lectura télica. Pero la raíz no es télica en sí misma: lo parece cuando, categorizada como verbo, se combina con un sustantivo cuantificable (Krifka 1998), que es lo más frecuente. Dado el caso, puede interpre-

\footnotetext{
${ }^{6}$ Nos basamos aquí en los datos que proporcionamos en Hernández Arocha (2014), a partir de búsquedas en el CREA efectuadas en 2011.
} 
tarse como atélica, si esquiva la cuantificación del objeto y bloquea la exteriorización de su argumento interno mediante un proceso de nominalización, como veíamos más arriba. Como todos los prefijos listados atribuyen información al subevento final de un accomplishment, la derivación se permite para $\sqrt{ }$ dec- y se bloquea para $\sqrt{ }$ habl-, excepto si este último sufre una coerción semántica. De hecho, la hipótesis que mantenemos aquí no es que la raíz contenga una restricción en su contenido semántico, sino que, dadas las propiedades de focalización que presenta, hace prevalecer una realización en detrimento de otras. Por lo tanto, si la raíz llegara a asumir el comportamiento opuesto, esto sería un indicio de que ha sufrido una coerción semántica y no una simple variante o realización sintáctica en pie de igualdad con su realización canónica.

Que esto es así lo muestra el verbo redecir. Como puso de relieve McCawley en el marco de la Semántica generativa y desarrollaron Dowty (1979: 264-269), von Stechow (1996) y otros en el ámbito de la semántica formal, el prefijo re-se restringe a una lectura restitutiva y no iterativa, como podrían denotar también sintagmas adverbiales como de nuevo. Como se observa en (21-22), el sintagma de nuevo puede asumir, junto a una lectura restitutiva, en el que el subevento que se ve modificado es el interno o final (21a), una iterativa, donde es el evento completo, no solo el estado resultante, el que se ve modificado. El prefijo re-, por el contrario, restituye el estado resultante del evento, pero es incapaz de reiterar el evento al completo, como se aprecia en la dificultad de interpretación de (22b), donde el contexto obliga al prefijo a que denote una repetición de toda la acción. Lo mismo se confirma con mayor claridad en (23). El verbo redecir se muestra reacio a asumir lecturas que no sean restitutivas.

(21) a. No me hagas decir de nuevo lo dicho.

b. No me hagas redecir lo dicho.

(22) a. No me hagas decir de nuevo que vengas.

b. No me hagas redecir que vengas.

a. ¿Podrías decirnos de nuevo lo que el presidente dijo en la reunión?

b. *.Podrías redecirnos lo que el presidente dijo en la reunión?

En el caso de hablar, la focalización del argumento más prominente produce un único evento complejo que podría ser reiterado (24a), pero que pierde la capacidad de acceder a los subeventos internos, de modo que la lectura restitutiva se bloquea y la derivación con $r$ - se rechaza (24b).

a. ¿Podrías hablar de nuevo, pero más alto?

b. *iPodrías rehablar, pero más alto? 
Este carácter interno lo presenta de igual modo el resto de prefijos, con algunas diferencias que no afectan a lo expuesto7. Así, desdecir(se) denota 'negar lo ya dicho' y no 'revertir la acción de decir' como en deshacer o desempaquetar. Asimismo, predecir denota 'hacer mediante la palabra que el lenguaje denote $\mathrm{X}$ antes [de que ocurra X]' y no 'hacer anteriormente mediante la palabra que el lenguaje denote X'. Del mismo modo, contradecir denota 'decir algo en contra de (lo que ha dicho) alguien' y no 'decir de forma contraria algo'. Todos ellos asumen, como decimos, una modificación interna y rechazan la modificación externa del evento. De nuevo, por esta razón esta clase de prefijos excluye combinarse con hablar.

\subsection{LAS RAÍCES Y LA SUfIJACIÓN}

De entre los sufijos, hay una clase que se orienta a la selección del argumento más interno o incrustado de la acción, llamada nomina actionis, y otra que selecciona el argumento más prominente, conocida como nomina agentis. Partiendo de este hecho y teniendo en cuenta los rasgos de focalización de las raíces, esperaríamos encontrar una distribución complementaria en ambas familias de palabras, como de hecho se muestra en la tabla 3.

\begin{tabular}{ccc}
\hline \multicolumn{2}{c}{ TABLA 3. RESTRICCIONES EN LA SUFIJACIÓN } \\
\hline & DECIR & HABLAR \\
\hline -ción & $\checkmark$ & $X$ \\
\hline -dor & $\checkmark$ & $\checkmark$ \\
\hline -nte & $\checkmark$ & $\checkmark$ \\
\hline -duría & $x$ & $\checkmark$ \\
\hline
\end{tabular}

Efectivamente, tenemos dicción, pero no tenemos hablación. Roßdeutscher (2014) explica que esta es una restricción que se cierne universalmente sobre los inergativos (*bailación, ${ }^{*}$ trepación, ${ }^{*}$ rascación, ${ }^{*}$ mordición, etc.) y nosotros creemos que es precisamente debido a la causa que hemos descrito. Veamos los siguientes casos. Como ambos verbos poseen un argumento externo (si bien solo hablar lo tiene focalizado), ambos verbos producen un adjetivo calificativo, pero con la orientación que conviene a la focalización: decidor se dice tanto de un hecho que constituye en sí mismo un símbolo como, bastante menos frecuente, prácticamente en desuso, de una persona, al tiempo que hablador designa únicamente una persona y no puede denotar un hecho. El participio activo -nte modifica igualmente a ambos pero, cuando se trata de resal-

7 Este argumento ha sido defendido por Martín García (1998: 204) en el marco teórico de la semántica conceptual de Jackendoff y pueden consultarse también en esta misma monografía las funciones semánticas básicas del prefijo. Agradezco a uno/a de los revisores anónimos la referencia a esta obra. 
tar de nuevo el argumento externo, reaparece la distribución complementaria: tenemos el conjunto de cosas expresadas por el hablador, esto es, la habladuría, pero no el conjunto de cosas expresadas por el decidor, esto es, la *deciduría (Hernández Arocha 2014, 2016a, b y las referencias ajenas y reseñas propias allí contenidas).

Tenemos, además, los casos de derivados en -ble, que presentan una complejidad mayor. Este sufijo accede al argumento interno de la acción, el menos prominente, y lo designa como referente que puede ser afectado por la denotación del verbo base ${ }^{8}$. Como es el interno el argumento que focaliza $\sqrt{ }$ dec-, el derivado decible es enteramente composicional, morfológica y semánticamente. En el caso de la raíz $\sqrt{ } h a b l-$, la derivación resulta abstrusa, dado que el sufijo no puede acceder a la focalización de un argumento interno. Pero, como hemos destacado en otras ocasiones (Hernández Arocha 2014, 2016a, b), el verbo es transitivizable si el objeto atribuye un rasgo al argumento focalizado, de modo que el objeto de (25b) no denotaría un problema en general, sino uno que afecta a los hablantes, o el pronombre $l o$ en (25c) tampoco designa un tema cualquiera, sino el que concierne a los hablantes. Sin duda, la alternancia del beneficiario facultativo que hemos añadido $\left({ }^{*}\right.$ selnos $)$ nos advierte que no afecta a cualquier otro participante. Todo lo expuesto explica por qué la percepción de agramaticalidad va disminuyendo de (25a) hasta (25c) conforme la interpretación semántica se aproxima a un posible argumento interno, pero, dado que no llega a encontrarlo, la focalización externa impide que el derivado resultante, hablable, se perciba con la naturalidad con la que lo hace decible.
a. He hablado con ella.
a. '?"Es una persona hablable 'una persona con la que se puede hablar'.
b. Tenemos que hablar el problema.
b'. "Es un problema hablable 'un problema del que podemos hablar'.
c. Tenemos que hablar(*se/nos)lo.
c'. 'Eso es hablable.

En resumen, todo parece indicar que las propiedades de la raíz controlan la productividad de la morfología poniendo a disposición y vetando casillas en la familia de palabras y, por lo tanto, determinando de forma decisiva su amplitud (size). Siendo la raíz la matriz generadora de toda familia, la importancia que recae en la raíz, en detrimento de la afijación, recae en el concepto de familia, en detrimento de la morfología?

${ }^{8}$ Con esta aproximación basada en la jerarquía lógica y no en el contenido temático pretendemos desengranar el mecanismo semántico que subyace al papel temático TEMA y que ha sido tomado en numerosas ocasiones como la principal restricción de selección del sufijo ( $c f$., por ejemplo, De Miguel 1986: 181). Agradezco a uno/a de los revisores anónimos la referencia a este estudio.

9 Téngase en cuenta que existe una opinión generalizada y, a mi juicio, bastante ingenua de que las familias representan la adjunción de una raíz a muchos afijos (explícitos, no cero) y, por lo tanto, son grupos de (más de 2) palabras emparentadas a través de la raíz. Considérese que, ante todo, la familia es un conjunto y, como tal, no reduce su cardinalidad a 2. En Teoría de Conjuntos, 


\section{CONCLUSIONES}

La idea que hemos querido trasmitir a lo largo de este trabajo es que las raíces no deberían imaginarse como puntos terminales de la derivación, como alveolos que nutren el árbol sintáctico con propiedades idiosincrásicas sin relevancia para su estructura. Por el contrario, este tipo de unidades debería concebirse, en nuestra opinión, como troncos, es decir, como aquellos elementos que dan sustento a la estructura de las ramas, la sintaxis explícita, pero que, al mismo tiempo, representa el punto de convergencia de todas las raíces, provenientes de la sintaxis implícita, de la geometría del evento. Efectivamente, estos nodos informativos se encuentran en el punto de intersección entre el álgebra del evento mental y la de la sintaxis explícita, de modo tal que se podrían concebir como punto de interfaz sintaxis/semántica o sintaxis/cognición.

Creemos, con los modelos distribuidos como el exosquelético, que estas unidades no están necesariamente categorizadas ni provistas de aspecto léxico, pero diferimos de ellos en nuestra defensa de la hipótesis de que albergan la información suficiente como para manifestar una categoría prototípica y, con ella, hacer germinar la valencia y el aspecto léxico canónicos. Esto implicaría que las manifestaciones restantes se producen mediante coerciones semánticas y no como simple generación espontánea del sistema sintáctico. Es más, pensamos que este cambio de perspectiva no afectaría en nada a un modelo distribuido, dado que lo único que conseguimos es reducir la capacidad generativa del sistema para acercarla lo más posible a lo que el hablante dice normalmente (a lo que la norma atestigua), aligerando de este modo el proceso de aprendizaje y obligando así a interpretar mediante coerción, esto es, mediante esfuerzo cognitivo adicional, los casos periféricos. Tales epifenómenos pueden ser considerados como periféricos por cualquier hablante, como creemos, podría demostrarse, dado el caso, mediante cualquier estudio de corpus. Esto no conlleva necesariamente un salto hacia el lexicalismo radical, dado que podría adaptarse este concepto de raíz al modelo de la llamada sintaxis léxica (Hale / Keyser 2002) o first phase syntax (Ramchand 2008), si bien el autor de estas líneas prefiere una aproximación categorial, que reserve el léxico para el álgebra de la semántica y la computación de aquellas proyecciones que sean eminentemente semánticas (como $p$ o la interpretación agentiva de $v$ en la figura 3 ) y restrinja la sintaxis a la llamada «sintaxis explícita».

el conjunto de cardinalidad 1, el llamado «singleton», es, efectivamente, un conjunto, así como lo es también el conjunto vacío. Por otra parte, en casos como el inglés, donde tenemos open (adjetivo), open (verbo ergativo), open (verbo causativo), tenemos una familia de palabras, con varios miembros, aunque solo tengamos una única raíz/lema en nuestro léxico mental. Esto podría llevar al error de pensar que, en lenguas con morfología distribucional, no existen familias de palabras, aunque sus mecanismos distribucionales de generación sean productivos y frecuentes, al tiempo que los de lenguas con morfología explícita, a los que no se les niega el estatus familiar, sean en muchas ocasiones totalmente improductivos o testimoniales. Para una definición actualizada del concepto de familia, véase Hernández Arocha (2016a). 
Este tipo de propuesta dista mucho de ser novedosa, puesto que se inspira, de hecho, en el análisis de Kamp para adjetivos intensionales de tipo former (Dowty / Wall / Peters 1981: 183), análisis que se ha convertido en la aproximación estándar y más consistente en la semántica formal. Nuestra aportación radica simplemente en que, concibiendo las raíces como funciones intensionales de segundo orden, explicamos un conjunto considerable de fenómenos que de otro modo se dispersan inconexos y le devolvemos al concepto de "familia de palabras» la importancia que se le niega en la lingüística teórica (especialmente la sintacticista) y que se le concede, por el contrario, en la (neuro)psicología.

Recibido: mayo de 2019; ACEPTAdo: noviembre de 2019. 


\section{BIBLIOGRAFÍA}

Acedo-Matellán, Víctor y Jaume Mateu, (2014): «From syntax to roots: A syntactic approach to root interpretation", en Alexiadou, Borer y Schäfer (eds.), 14-32.

Alexiadou, Artemis (2001): Functional structure in nominals: Nominalization and ergativity, Amsterdam: John Benjamin.

Alexiadou, Artemis, Hagit Borer y Florian Schäfer (eds.) (2014): The Syntax of Roots and the Roots of Syntax, Oxford: Oxford University Press.

Augst, Gerhard (2000): «Die Mächtigkeit der Wortfamilien - Quantitative Auswertungen zum ,Wortfamilienwörterbuch der deutschen Gegenwartssprache'», en Irmhild Barz, Marianne Schröder y Ulla Fix (eds.), Praxis und Integrationsfelder der Wortbildungsforschung, Heidelberg: Winter, 1-18.

Augst, Gerhard (2009): Wortfamilienwörterbuch der deutschen Gegenwartssprache, Berlin/Boston: De Gruyter.

BALdRIDGe, Jason y Frederick Hoyt (2015): «Categorial Grammar», en Tibor Kiss y Artemis Alexiadou (eds.), Syntax. An international Handbook, Berlin/Boston: De Gruyter, 5-25.

Batista, José Juan y Encarnación Tabares Plasencia (2011): «Notas sobre el aspecto en griego moderno, español y alemán», en Carsten Sinner y Elia Hernández Socas (eds.), La expresión de tiempo y espacio y las relaciones espacio-temporales. Enfoques contrastivos, Frankfurt am Main: Peter Lang, 35-50.

Borer, Hagit (2013): Taking Form: Structuring Sense, vol. III, Oxford: Oxford University Press.

Borer, Hagit (2014a): «The category of roots», en Alexiadou/Borer/Schäfer (eds.), 112-148.

Borer, Hagit (2014b): «Wherefore roots?», Theoretical Linguistics 40, 3: 343-359.

Carpenter, Bob (1997): Type-Logical Semantics, Cambridge: MIT.

Сномsкy, Noam (1972 [1970]): «Remarks on nominalization», en Noam Chomsky, Studies on Semantics in Generative Grammar, De Hague: Mouton / De Gruyter, 11-61.

Сномкку, Noam (1995): The minimalist program, Massachusetts: MIT.

Coseriu, Eugenio (2007 [1981]): Sprachkompetenz, Tübingen: Narr.

CREA = Real Academia Española: Corpus del español actual, http://www.rae.es, 14/10/2011.

Cruse, David A., et al. (eds.) (2002): Lexikologie/Lexicology. Ein internationales Handbuch zur Natur und Struktur von Wörtern und Wortschätzen/An International Handbook on the Nature and Structure of Words and Vocabularies, vol. I, Berlin/New York: De Gruyter.

De Jong, Nivja H., Robert Schreuder y Harald BaAyen (2000): «The morphological family size effect and morphology", Language and cognitive processes 15, 4/5: 329-365.

De Miguel, Elena (1986): «Papeles temáticos y regla de formación de adjetivos en -ble», Dicenda: Cuadernos de filología hispánica 5: 159-182.

Dowty, David (1979): Word Meaning and Montague Grammar. The Semantics of Verbs and Times in Generative Semantics and in Montague's PTQ, Dordrecht: Reidel.

Dowty, David R., Robert E. Wall y Peters Stanley (1981): Introduction to Montague Semantics, Dordrecht: Reidel.

Gallego, Ángel J. (2014): «Roots and phases», en Alexiadou, Borer y Schäfer (eds.), 192-207. 
García PAdrón, Dolores (2007): «La dispersión semántica en las familias de palabras». Homenaje a Antonio Lorenzo. Revista de Filología de la Universidad de La Laguna 25: 215-224.

Gомвосz, Eszter (2013): Kontrastive Wortfamilienanalyse. Deutsch-Ungarisch, Mannheim: Institut für Deutsche Sprache.

Hale, Ken y Samuel Keyser (2002): Prolegomenon to a theory of argument structure, Cambridge: MIT.

Harley, Heidi (2009): «The morphology of nominalizations and the syntax of $v \mathrm{P}$ », en Monika Rathert / Anastasia Giannadikou (eds.), Quantification, Definiteness and Nominalization, Oxford: Oxford University Press, 320-342.

Hernández Arocha, Héctor (2013): «Reseña: Luis Alexis Amador Rodríguez (2009): «La derivación nominal en español: nombres de agente, instrumento, lugar y acción», Zeitschrift für Romanische Philologie 129, 1: 65-68.

Hernández Arocha, Héctor (2014): Las familias de palabras. Relaciones entre morfología, semántica y estructura argumental en las raices «dec(ir)» $\mathrm{y}$ «sag(en)», Berlin/Boston: De Gruyter.

Hernández Arocha, Héctor (2016a): Wortfamilien im Vergleich. Theoretische und historiographische Aspekte am Beispiel von Lokutionsverben, Frankfurt am Main: Peter Lang.

Hernández Arocha, Héctor (2016b): «Locución y modelos para su descripción semántica», Lebende Sprachen 61, 1: 117-174.

Hernández Arocha, Héctor (en preparación): Adjuncts and their interfaces. A CCG approach to verb-particle contructions in Germanic and Romance, Habilitationsschrift, Erfurt: Universität Erfurt.

Hernández Arocha, Héctor y Elia Hernández Socas (2019a): «Räumlichkeit und Aspektualität ablativer Verbzusatzstrukturen am Beispiel lexikalischer Übereinstimmungen», Sprachwissenschaft 44, 1: 111-157.

Hernández Arocha, Héctor y Elia Hernández Socas (2019b): «The Conceptual Basis of Ablativity», Journal of Cognitive Linguistics 17, 2: 513-132.

Hernández Arocha, Héctor, José Juan Batista y Elia Hernández Socas (2011): «¿Se puede medir el significado interlingüísticamente? Valores locativos, temporales y nocionales en la comparación de preverbios griegos, latinos, españoles y alemanes», en Carsten Sinner, Elia Hernández Socas y Christian Bahr (eds.), Nuevas aportaciones de los enfoques contrastivos al estudio de la expresión del tiempo y del espacio, Frankfurt am Main: Peter Lang, 73-92.

Hernández Socas, Elia (2020): La prefijación ablativa y su representación semántico-conceptual. Estudio contrastivo de equivalencias interlingüisticas entre alemán, lenguas clásicas e iberorromances, Berlin/Boston: De Gruyter.

Hernández Socas, Elia y Héctor Hernández Arocha (en prensa): «Restricciones tipológicas en la incorporación verbal de adjuntos», Onomázein.

Jacobson, Pauline (2014): Compositional Semantics, Oxford: Oxford University Press.

KrifKa, Manfred (1998): «The origins of Telicity» en Susan Rothstein (ed.), Events and Grammar, Dordrecht: Reidel, 197-235.

LAmbeк, Joachim (2014): From rules of grammar to laws of nature, New York: Novinka.

Levin, Beth y Malka Rappaport Hovav (2013): «Lexicalized meaning and manner/result complementarity», en Boban Arsenijević, Berit Gehrke y Rafael Marín (eds.), Subatomic Semantics of Event Predicates, Dordrecht: Springer, 49-70. 
Levinson, Lisa (2014): «The ontology of roots and verbs», en Alexiadou, Borer y Schäfer (eds.), 208-229.

Lowenstamm, Jean (2014): «Derivational affixes and roots: Phasal Spell-out meets English Stress Shift», en Alexiadou, Borer y Schäfer (eds.), 230-258.

Marantz, Alec (1997): «No escape from Syntax: Don't try a morphological analysis in the privacy of your own lexicon", University of Pennsylvania Working Papers in Linguistics 4, 2: 201-225.

Marantz, Alec (2001): Words. Manuscrito: MIT y NYU.

Martín García, Josefa (1998): La morfología léxico-conceptual: las palabras derivadas con re-, Madrid: Ediciones de la UAM.

Martín Padilla, Kenia (2015): La familia de palabras duc-. Significados lingüísticos y sentidos culturales, tesis doctoral, La Laguna: Universidad de La Laguna.

Mateu, Jaume (2014): «Argument structure», en Dins A. Carnie et al. (eds.), The Routledge Handbook of Syntax, New York: Routledge, 24-41.

Montague, Richard (1974 [1970]): «The proper treatment of quantification in ordinary English», en Richard Thomanson (ed.), Formal philosophy. Selected papers of Richard Montague, New Haven/London: Yale University Press, 247-270.

Morera, Marcial (2007): La gramática del léxico español, Albacete: Abecedario.

Mulder, Kimberley, Ton Dijkstra, Robert Schreuder y Harald BaAyen (2014): «Effects of primary and secondary morphological family size in monolingual and bilingual word processing», Journal of Memory and Language 72: 59-84.

Pena, Jesús (2011): «La alomorfía en el interior de las familias léxicas», en José Pazó Espinosa, Irene Gil Laforga y María Ángeles Cano Cambronero (coords.), Teoría morfológica y morfología del español, Madrid: UAM, 109-132.

Pustejovsky, James (1995): The generative Lexicon, Massachusetts: MIT.

Ramchand, Gillian C. (2008): Verb Meaning and the Lexicon. A First-Phase Syntax, Oxford: Oxford University Press.

Rohlfing, Katharina J. (2013): Frühkindliche Semantik, Narr: Tübingen.

Rossdeutscher, Antje (2014): "When roots license and when they respect semantico-syntactic structure in verbs», en Alexiadou, Borer y Schäfer (eds.), 282-309.

Splett, Jochen (2009): Deutsches Wortfamilienwörterbuch. Analyse der Wortfami-lienstrukturen der deutschen Gegenwartssprache, zugleich Grundlegung einer zukünftigen Strukturgeschichte des deutschen Wortschatzes, Berlin/New York: De Gruyter.

STECHOw, Arnim von (1996): «The different readings of wieder 'again': A structural account», Journal of Semantics 13: 87-138.

Steedman, Mark (2000): The syntactic process, Massachusetts: MIT.

Steedman, Mark (en preparación): Combinatory Categorial Grammar. Manuscrito.

Van Valin, Robert D. y Randy La Polla (1997): Syntax: Structure, meaning, and function, Cambridge: Cambridge University Press.

Wотјак, Gerd (2006): Las lenguas, ventanas que dan al mundo, Salamanca: Servicio de Publicaciones de la Universidad de Salamanca.

Wunderlich, Dieter (2012): «Lexical Decomposition in Grammar», en Markus Wernig, Wolfram Hinzen y Edouard Machery (eds.), The Oxford handbook of compositionality, Oxford: Oxford University Press, 307-327. 